NBER WORKING PAPER SERIES

\title{
PUZZLES IN THE FOREX TOKYO "FIXING": ORDER IMBALANCES AND BIASED PRICING BY BANKS
}

\author{
Takatoshi Ito \\ Masahiro Yamada \\ Working Paper 22820 \\ http://www.nber.org/papers/w22820 \\ NATIONAL BUREAU OF ECONOMIC RESEARCH \\ 1050 Massachusetts Avenue \\ Cambridge, MA 02138 \\ November 2016
}

The first author acknowledges financial support Japan Society for the Promotion of Science, Grant-in-Aid for Scientific Research A-25245044. The second author acknowledges financial support Grant-in-Aid for Scientific Research A-24243031. The authors are grateful to comments on an earlier version by Alain Chaboud, Robert Engle, Martin Evans, Michael Melvin, Shmuel Baruch, and Sadayoshi Takaya. We are also indebted to a market participant in a bank who wishes to be anonymous, for his insights on the Tokyo fixing. A part of this paper contains some materials of our previous unpublished working paper, NBER working paper no 21518, September 2015.Our earlier working paper has been divided into two and each half has been substantially revised and updated. The views expressed herein are those of the authors and do not necessarily reflect the views of the National Bureau of Economic Research.

NBER working papers are circulated for discussion and comment purposes. They have not been peer-reviewed or been subject to the review by the NBER Board of Directors that accompanies official NBER publications.

(C) 2016 by Takatoshi Ito and Masahiro Yamada. All rights reserved. Short sections of text, not to exceed two paragraphs, may be quoted without explicit permission provided that full credit, including $(\odot$ notice, is given to the source. 
Puzzles in the Forex Tokyo "Fixing": Order Imbalances and Biased Pricing by Banks

Takatoshi Ito and Masahiro Yamada

NBER Working Paper No. 22820

November 2016

JEL No. D43,D47,F30,F31,F33,G12,G15

\begin{abstract}
$\underline{\text { ABSTRACT }}$
"Fixing" in the foreign exchange market is a market practice that determines the bid-ask-midpoint exchange rate at a scheduled time, 10am in Tokyo and 4pm in London. The fixing exchange rate is then applied to the settlement of foreign exchange transactions between banks and retail customers including broker dealers, institutional investors, insurance companies, exporters and importers, with varying bid-ask spreads.

Our findings for the Tokyo fixing are summarized as follows. (1) Price spikes in the Tokyo fixing are more frequent than in the London fixing. (2) The customer orders are biased toward buying the foreign currencies, which is predictable. (3) Before 2008, the fixing prices set by banks were biased upward, and higher than the highest transaction price during the fixing time window. (4) Even after 2008, the fixing prices announced by banks were still above the median transaction price during the fixing window, suggesting that banks make predictable profits. (5) The calendar effects also matter for determination of the fixing rate and the price fluctuation around fixing time.
\end{abstract}

Takatoshi Ito

Columbia University

School of International and Public Affairs

International Affairs Building

Room 927, (MC 3333)

420 West 118th Street

New York, NY 10027

and NBER

ti2164@columbia.edu

Masahiro Yamada

Hitotsubashi University

2-1 Naka

Kunitachi, Tokyo, 186-8601

Japan

m.yamada@r.hit-u.ac.jp 


\section{Introduction}

"Fixing” in the foreign exchange market is a market practice that determines the bid-ask mid-point exchange rate around a pre-announced time of the day. The fixing exchange rate is then applied to the settlement of foreign exchange transactions between banks and retail customers including broker dealers, institutional investors, insurance companies, exporters and importers, with varying bid-ask spreads.

There are two major fixings in a day, one at 10am in Tokyo applicable mostly to Japanese banks' transactions with its retail customers during Tokyo business hours; and another at 4pm in London, applicable to retail transactions between retail customers and London-based banks. (Times in this paper are local times unless otherwise noted.) Distinctive spikes in deal volumes at both times are well-known in many papers analyzing high-frequency data and market microstructure of the foreign exchange market. However, the price (interchangeably used to mean the exchange rate below) behavior around the fixing times has not been carefully analyzed before with a few exceptions (Evans (2014) and Melvin and Prins (2015)).

Although the fixing practices in Tokyo and in London share common features, important institutional differences exist. First, both fixings are to set a common price for a bank and its retail customers. In London, one price set by the WM/Reuters is applicable to all banks in the London market, while in Tokyo each bank sets its own fixing price, which is applicable to its own customers only. Second, the fixing is done once a day in both markets, but which time of the day matters: 4pm in the London market means that the price is set at the end of the business day, while 10 am in Tokyo is still near the beginning of the business day. The London fixing rate applies only to the pre-fixing orders, while the Tokyo fixing rate applies to transactions of both pre-fixing and post-fixing orders, until the end of Tokyo business hours. Third, although both fixing rates are calculated from the market transaction rates, the linkage is explicit in London, as it is a median of sampled transactions during the one-minute window, 4:00:00 pm plus/minus 30 seconds, while the 10am announcement of the fixing rates by Japanese banks are based on its own transactions at exactly at 9:55:00 am. Lastly, the London 
fixing rate is primarily used to value international portfolios. This particular role of Forex fixing induces additional hedging demand from international fund managers who want to trade at the fixing rate to minimize tracking errors (Melvin and Prins (2014)). The Tokyo fixing, however, does not have this role.

When banks receive unbalanced retail orders (excess demand or supply) of foreign exchanges among the retail orders) that are to be traded at the fixing rate, banks need to avoid carrying out orders in the interbank market at wrong prices. Hereafter "excess" demands are interchangeably used with customer order imbalances. Excess demands for foreign exchange are at the retail customer levels without the knowledge of the fixing price. When customer orders are executed by the bank in the interbank market, "excess" demands are absorbed by liquidity providers on the opposite side of the market. Thus, as banks hold the retail orders that the fixing price is applied to, they aim to make the average price of transactions (hereafter the inventory price) close to the fixing price.

In London, since banks do not know what the fixing price will be, they have an incentive to carry out trades as many as possible at or near what the median price would be during the one-minute fixing window. Banks try to keep the volatility minimized by trading in small amounts, which limit price impacts.

In Tokyo, since each bank can set its idiosyncratic fixing price, the bank can easily avoid the deviation between the inventory price and the fixing price for the retail orders prior to the fixing time. However, Tokyo-based banks face different problems. The bank’s fixing price is valid for the rest of the day. If the fixing price deviates from the fundamentals or other banks' fixing prices, the bank is at risk of being swamped by unwanted customer trades for the rest of the day. This imposes a natural restraint for a bank not to deviate too much from the median transaction price during the fixing window. For the bank's fixing price, the bid-ask spread for customer trades is set to be plus/minus 100 basis points from the fixing (mid-point) price. In London, it was not supposed to have a bid-ask spread before the reforms of February 2015.

Both in London and in Tokyo, banks would behave differently if they knew in advance the order 
imbalances of the market. If and when the London dealers know the order imbalances beforehand, informed dealers would have a few tactics to increase their profits. Order imbalances most likely push the price up or down during the fixing window, so that the informed dealers can front-run orders before the window starts. Then banks will secure a price of accumulated transactions (inventory price) that deviate from a median price to be. An alternative tactic is to drive the price up, or down, during the fixing window, exaggerating the customer order imbalances, so that the price that the customers have to pay become higher than the bank's inventory price. One would imagine it is difficult to obtain information on such customer order imbalances or influences on median prices since the foreign exchange markets are deep and liquid, especially at the time of fixing. The collusion scandal came to light in 2013. ${ }^{4}$ The alleged collusion and banks' agreement for fines is an interesting story, but we defer the topic to another paper. Here we concentrate on the Tokyo fixing.

In Tokyo, if and when a bank knows there exist order imbalances, a bank can employ a few tactics to avoid risk, or rather, increase profits. Suppose that the bank receives retail orders of excess demands for foreign currencies (say, the US dollar) and the bank can infer that received order flows have a strong positive correlation with the market order flows. The bank becomes reasonably certain that the fixing price will move up. First, the bank can front run the order when the price is still stable. This will keep the inventory price down. Second, the bank can buy more during the fixing time window to drive up the price. It is good to record a high fixing price so that the bank can determine its own fixing price higher than the inventory price. Volatility is welcome by the bank. In Tokyo, the discretionary power of setting the fixing rate to the bank's advantage seems larger, but there is risk that orders after the fixing time may be biased against the bank's wish.

The time-series of the daily fixing prices of two large banks in Tokyo are compared to the market prices during the fixing time window, where the latter is calculated from the tick-by-tick, high-

${ }^{4}$ For the detail of the scandal, please refer to the series of FCA final notice to five banks: The Royal bank of Scotland (ref.121882), HSBC bank (ref.114216), Citibank (ref.124704), UBS (ref.186958), JP Morgan Chase bank (ref.124491). 
frequency data of the ICAP-EBS data set. Consider the US dollar-Japanese yen (USD/JPY) market. In the data set, two types of transactions are distinguished. When the bid quote is hit, i.e., bid-side transactions occur, it is an act of the market-takers' selling order of the US dollar; and when the ask quote is hit, i.e., ask-side transactions occur, it is an act of the market-takers' buying order of the US dollar. By comparing the deal volumes of bid-side and ask-side transactions, it can be inferred whether buying pressure or selling pressure is stronger. When transactions occur on the ask side more than the bid side in a particular time period, it is evidence of excess demand for US dollars (vis-à-vis the Japanese yen) by retail customers and banks’ proprietary trading, if any. Order imbalances are said to have existed.

The novelty of this paper is examining the institutional details of the Tokyo fixing and the price and liquidity behavior around the fixing by using tick-by-tick data. Major findings are as follows. First, at the moment of the Tokyo fixing (or 9:55am), there is an extreme concentration of trades, generating frequent price spikes. Second, in the Japanese markets, there are persistent order imbalances in the direction of excess demand for the US dollar. Because major customers for the fixing transactions are importers rather than exporters, the order imbalances incline to buying foreign currencies (USD and EUR). In addition, each bank can set their own fixing rate based on their transactions in the Forex markets, which induces the incentive for banks to trade at extreme prices. As a result, the excess demand for foreign currencies affects the market and generate frequent price spikes. Because these peculiar order imbalances reflect nothing more than the temporal imbalances of demand/supply of currency, the appreciated price reverses after the fixing time. Consequently, the movement of prices around fixing tends to become hump-shaped.

Lastly, prior to 2008, Japanese banks tended to set the fixing rate higher than the ceiling of the trading price range during the fixing window. Given the excess demand for US dollars from retail customers, the higher the fixing price (compared to the bank's inventory price), the more profits the banks could earn. A major reason for this gap is the swap point for the interest differential between US and Japan. Since there are the persistent imbalances to buying the foreign currency, the swap point 
is implicitly incorporated in the mid-rate. The intraday imbalance of customer orders also affects the degree of this gap.

The rest of the paper is organized as follows. Section 2 is the literature survey. Section 3 gives details of the "fixing” practice in the Forex market as well as details of the Tokyo fixing. Data used in this paper need detailed explanations that is provided in Section 4. Section 5 shows the empirical puzzles that are observed in the Tokyo fixing. Section 6 concludes the paper.

\section{The Literature Review}

It is well known that transaction volumes tend to skyrocket around the Tokyo 9:55 am fixing, London 4:00 pm fixing, US major macro announcements (8:30 EST), and the New York option cuts (10:00 EST). The volume spikes are well documented in the existing literature on intraday, highfrequency exchange rate behaviors. However, few studies price behavior around the time of fixing. Other than the major spikes mentioned above, there are minor spikes of transaction volumes at different times of the day. One of those times correspond to times of macro-statistical releases, such as GDP and CPI. When a macro statistical announcement contains surprises (unexpected changes), then the price will jump to a new equilibrium (Ito and Hashimoto (2006), Chaboud et al. (2004)). The price jump can be regarded as a price discovery process to a new equilibrium. In contrast, the price jumps and spikes during the fixing window, representing only temporary order imbalances and liquidity shortages, which is expected not to result in such jumps to a new equilibrium. A few papers have investigated the topic of fixings in the foreign exchange (Forex) markets. Melvin and Prins (2015) investigated the transactions around the fixing that are related to the hedging of international portfolios. Equity investors hedge the growth of equities of a foreign country by selling the currency of that country. The timing of the hedging trade is typically at the London fixing at the end of the month. By using high-frequency Forex transaction data and propriety data that identifies order flows from non-banking sectors, Melvin and Prins (2015) confirmed that the past positive equity return in a country is associated with the currency depreciation of that country at the end-of-month London 
fixing. Because of the liquidity provision by arbitrageurs, they note, the profits from this association are consistent with the reasonable limits to arbitrage. In line with this research, Evans (2014) investigated the Forex rate behavior around the London fixing. The paper emphasized the negative autocorrelation of the Forex rate between the pre- and post-fixing periods, particularly at the end-ofmonth trading day. This finding is commonly observed across all the time periods and currency pairs.

\section{Fixing in the Forex Market}

Before the Tokyo fixing is explained, the London fixing is reviewed. In London, the WM/Reuters announces the fixing price, that is applicable to all banks, just after 4:00 pm, based on prices of transactions that took place in the one minute window around 4:00 pm (that is, from 15:59:30 to 16:00:30). The WM/Reuters fix is widely used as the price for customer trades in the London and New York markets. It has been established in literature that within the 24-hour cycle, transaction volumes are highest around 1:00 pm to 4:00 pm in London (8am to 11:00 am in New York). After the 4:00 pm fixing in London, transaction volumes and price volatility quickly diminish. The banks have accumulated the customer orders of the day by 4:00 pm London so that there will be no remaining uncertain exposures after the 4:00 pm fixing. ${ }^{5}$

The fixing prices, different by banks, in the Tokyo market are announced at JST 10:00 (GMT 1:00) by banks. Each bank decides the fixing price individually. The bank supposedly determine the fixing price based on the spot transaction prices at around JST 9:55:00. There is no explicit window or formula that the banks have to follow to determine the fixing price. According to market participants, although the bank may refer to its own transaction prices at around JST 9:55:00, there is no common

${ }^{5}$ In addition to the London fixing and the Tokyo fixing time windows, there are a few other volume spikes known to exist. One is the time of US Macroeconomic Announcement times (most important at 8:30 am) and New York Option Cut (10am). For the former, see Andersen et al. (2003), Evans and Lyons (2008) and Hashimoto and Ito (2010) for price impacts of a surprise in macroeconomic announcements. For New York Option cut, see Ni, Pearson, and Poteshman (2005) and Chaboud et al. (2004). 
rules to derive the fixing rate for banks. In recent years, banks are allowed to fix the rates arbitrarily within the range in which they have made their transactions around JST 9:55. ${ }^{6}$ This is a contrast to the London fixing which is provided by a third-party (i.e., WM/Reuters) and has a window period of 30 seconds before and after 16:00 London time, to fix the rate, and the fixing price is common to all banks. $^{7}$

In the situation of the Tokyo fixing, banks tend to have an incentive to make deals at some extreme ranges, possibly helping determine the fixing rates with some flexibility. Such deals can appear several seconds around JST 9:55. Thus, fixing rates by each bank can deviate from the transaction prices with this institution. Then, what are the characteristics of this deviation of rates? How this institution affect the price behavior around JST 9:55?

Figure 1 illustrates a typical behavior of prices around the fixing.

Figure 1 about here

In this figure, the price has a transitory peak at the moment of fixing (9:55:00). The price moves up several basis points in a few seconds, and then comes back to the original position in the following few seconds. We call this a price spike, and pay particular attention to this type of price behavior. The spike at the fixing can be unfavorable for clients who submitted orders to trade at the fixing rate. On the other hand, the spike can be favorable for banks because they can use the extreme price as the fixing rate regardless of the volume. Because traders avoid the price impacts of carrying out large orders by splitting them, according to the standard market microstructure theory (e.g., Kyle (1985)), the price spike is very strange. The price spike is even stranger since it occurs when liquidity is ample. Theoretically, the transitory overshooting of the price is attributable to predatory trading behavior (Brunnermeier and Pedersen (2005)), or to trading that exploits the need of other investors to reduce

${ }^{6}$ This implicit rule was mentioned by market participants in interviews.

${ }^{7}$ As of February 2015, WM/Reuters had changed their rules to define the fixing rate; now they use a five minute window rather than one minute window. Details can be found at http://www.wmcompany.com/pdfs/WMReutersMethodology.pdf 
their positions at any price (fire sale). In the Tokyo fixing window, the retail clients are captive, and vulnerable to banks' monopolistic pricing, when order imbalances exist. This situation resembles that of predatory trading. WM/Reuters London fixing prevents this possibility by taking the median of the transaction price during the one-minute fixing window.

In Figure 1, the price moving up slightly from 9:53 to 9:55 and then moving down from 9:55 to 9:57 is suggestive of such front-running and reversal activities. Two factors explain such a gradual increase, followed by a spike at the time of fixing, followed by the gradual decline. First, the defensive motive. The bank has to deliver the foreign exchange at the fixing price to retail customers, no matter what the inventory price is. When the bank realizes the existence of order imbalances among its own retail customers before the fixing time window, for instance in the direction of excess demand for the US dollar the bank has an incentive to start executing orders to hold the eventual inventory price down. The banks typically conduct pre-hedging trades before the fixing times. ${ }^{8}$ However, the pre-hedging does influence the price slightly. This produces a gradual increase in the price toward the fixing time window. This explains the gradual increase toward the fixing time window. Because the trading for the needs of fixing has little impact on the true fundamentals, the price may eventually reverse after the fixing. Thus, the return before the fixing and the return after the fixing are expected to have negative correlation, if the arbitrage does not works enough to iron out the correlation. If traders (not necessarily banks) anticipate buying at 9:54, they may well start trading at 9:53, and 9:52, and so on. Thus, dollars can begin to appreciate gradually towards 9:55 and depreciate quickly after 9:55.

Second, there is a more aggressive tactic that explains the spikes. Banks with private information on customer order flows can likely infer that such price spikes at 9:55 am will occur at a high probability. Then under this assumption, they can make extra profit by purchasing USD/JPY at 9:54 am and sell them at 9:55 am. This type of trading parallels front-running in the equity market, but front-running trades are not prohibited in the Forex market. Suppose that the market wide order

\footnotetext{
${ }^{8}$ Hedge trades start 30 minutes before the fixing, said one market participant.
} 
imbalance is positively correlated with the order imbalance of a large bank. A large bank is capable of predicting a price spike during the fixing time window due to the order imbalances. Then, prior to the fixing time window, informed banks start trading at still stable prices in order to keep the inventory price down. Suppose that there is an order balance of excess demand for the US dollar. The informed bank aims at maximizing the profit margin, i.e., its own fixing price and the inventory price. By frontrunning, the bank can hold the inventory price down - this part is indistinguishable from the prehedging behavior. During the fixing time window, the bank has in incentive to drive up the price as much as possible to set a record that the bank's fixing price can be as high as possible. If Bank A's announced fixing price is widely different from Bank B’s announced fixing price, this may alarm the supervision authority or the retail customers. So, there is a natural limit to monopolistic pricing. In that sense, having a very high price trading record is important.

Both Melvin and Prins (2015) and Evans (2014) examine this particular movement of prices around the London fixing, and find negative correlations of currency returns especially when there are large needs for settlement, such as on the end-of-month trading day. Generally, banks can make a profit by trading on the information of customers’ order flows. Even before the fixing scandal emerged, this problem was discussed in academic studies (e.g., Ito, Lyons, and Melvin (2002), Evans and Lyons (1999)).

As mentioned in the introduction, each bank in Tokyo announces a bank-specific fixing rate. Are banks allowed to announce any price? Probably not. A bank can justify announcing the fixing rate that is within the range of the banks' actual transactions in the interbank market around the 9:55 am fixing. However, when the range is wide, and the setting of the rate is slightly on the appreciation (of the USD) side, banks that face more buying than selling from customers result in earning extra profits. This inference cannot be tested for individual banks, since the bid, ask, and deals in our data set do not have the banks' individual name tags. Instead we can compare individual banks' fixing prices with the volume weighted average price at 9:55 am.

There is one more - probably the most important - anomaly in the Forex market in Tokyo time. In 
general, on average buying and selling orders are balanced. Thus intraday returns cannot be different from random walks. However, just before the Tokyo fixing, the orders quite often become unbalanced, and the direction of order imbalances are predictable. Market participants argued to the authors of the paper that around the fixing period in the Tokyo market, the buying orders of foreign currency (US dollar and Euro) by importers regularly exceed the selling orders by exporters. It is commonly known that the USD tends to appreciate vis-à-vis the yen around the fixing time. This situation is more evident when large amounts of payments are due, typically on the days of the $5^{\text {th }}$, $10^{\text {th }}, 15^{\text {th }}, 20^{\text {th }}, 25^{\text {th }}$, and $30^{\text {th }}$, (hereafter $5^{\text {th }}$ and $10^{\text {th }}$ days) as well as the end-of-month trading day. ${ }^{9}$

Based on the observation above, we examine statistically the following: (1) whether there are such spikes of prices in the fixing time window around 9:55, (2) where there is gradual appreciation of foreign currency to the yen before 9:55, and (3) whether banks with private information set higher (or more appreciated dollars and euro) fixing rates than the median of interbank market rates around 9:55.

If the market is efficient and banks try to minimize their price impact, price spikes would be unlikely, no particular pattern of appreciation of Forex rate would be found, and the transaction prices in the market would replicate the fixing rate properly. Our empirical tests are set against these null hypotheses.

\section{Data}

\subsection{High-frequency Data}

In this section, our data set and their treatment are described. The main market exchange rate data are obtained as firm quotes and actual deal prices and volumes available from the trading platform of EBS: ${ }^{10}$

- ICAP EBS Level 5 (or Level 2) data (proprietary data but commercially available from ICAP

9 The Japanese call these dates "Go (5) tou (10) bi (day)."

10 Observations on Saturdays and Sundays (at GMT) are dropped, and so are observations on Christmas and New Years days. 
EBS) ${ }^{11}$

o Level 5 data: January 2006 to December 2013. Currency pairs: 'AUD-USD', 'EURGBP', 'EUR-JPY', 'EUR-USD', 'GBP-USD', 'USD-CAD', 'USD-CHF', 'USD-JPY'

o Level 2 data: January 1999 to December 2005. Currency pairs 'USD-JPY'

- $\mathrm{WM} / \mathrm{R}$ Closing rate (Reuters), available in the public domain:

o January 1999 to December 2013.

- Publicly disclosed fixing rate for Japanese banks: Mizuho Bank, Bank of Tokyo Mitsubishi (BTMU)
o January 1999 to December 2013 (BTMU in the public domain)
o January 2002 to December 2013 (Mizuho in the public domain)

A summary timetable disclosing a one day outlook of the Forex market is described in Table 1. In this research, we focused on the two fixings and did not report a detailed analysis regarding the announcements and option cuts.

Table 1 about here

ICAP EBS Forex dataset contains the information of deals and quotes at each time-slice. ${ }^{12}$ Each observation has time-stamped prices (transaction prices and limit order prices if available) and volume (transaction volumes, limit order volumes if available). The grid of time-slices has changed during the following periods: “one second” before January 22, 2008, “a quarter-second” from January 22, 2008 to August 31, 2009, and “a 100 millisecond” from August 31, 2009 to present. The minimum tick size, or pips, also has changed. It was traditionally two digits after the decimal point for USD/JPY and four digits after the decimal point for EUR/USD. It was decimalized (three digits for USD/JPY and five digits for EUR/USD) on March 7, 2011 and then rolled back to half pips after September 24, 2012.

The dataset has different levels of recording details: EBS Level 2 and EBS Level 5. In the Level 5

11 The data set was purchase with research grant to the first author.

12 ICAP EBS Forex data is high-frequency data which needs data cleaning. We provided a detailed data cleaning process when we introduced the methodology. 
dataset, each observation of the deal has buyer-initiated and seller-initiated deal volumes. The database, however, omits certain deals that show multiple transactions between time slices. The observation at a time-stamp (HH:MM:SS for example) contains the deals that occur between $t-1$ and $t$, where $t$ is by one second (HH:MM:SS). The recorded transaction prices at the time slice are the most extreme ones (highest paid and lowest given) during the time slice (one second window in Level 2).

The information of quote contains the limit order prices and volumes up to ten steps (tenth best) of the limit order book. ${ }^{13}$ This observation is a snapshot of the limit order book, which are recorded when any change occurs in the book. The dataset also contain quote counts. A quote count is the number of traders who are submitting limit orders at each step of the book.

Note that EBS allows negative spreads: the best ask price can be lower than the best bid price. This situation happens when the two entities at the book do not have credit lines. Also, when an observation has both a deal and a quote, the dataset does not specify the order of each transaction. We need to estimate the orders of transactions.

Level 2 dataset has a coarse frequency (every one second), and provides only the first best ask and bid prices. For most of the analysis in this paper, we use the level 5 data. We use the level 2 data before 2005 only for constructing the prices to demonstrate the comparison of the fixing rates.

WM/R closing rate is provided by Reuters Datastream. The fixing rates by the BTMU and by the Mizuho bank are obtained from their websites. WM/R closing rates are calculated during normal business hours when two or more trading centers (US, UK, Germany, and Japan) are open. The Tokyo fixing rates are not available on Japanese national holidays.

In following subsections, the intraday pattern of deals and liquidity is reviewed in order to

13 Although the data of limit order book have the record of quotes up to tenth steps, we limit our attention on the four best quotes. Some currency pairs sometimes lack the limit order data distant from the best. Even for major currency pairs, the tick between the limit prices tends to be large for such distant limit orders. We omit these distant limit orders because they are less likely to make the liquidity available. 
highlight how distinct the fixing window times are.

\subsection{Deal Spikes and Price impact}

The intraday pattern of transaction volumes of USD/JPY is examined in this subsection. We focus on USD/JPY because it is strongly affected by the Tokyo fixing. We note that other currency pairs also have a similar intraday pattern. For avoiding the confusion from daylight saving time, we use the sample when both the US and UK markets are under the daylight saving (summer) time.

Figure 2 shows the intraday pattern of (A) the ratio of absolute order imbalances to trading volumes, (B) order imbalances, (C) trading volumes, and (D) price impacts. Each has a sampling frequency of 15 seconds. The horizontal axis shows the intraday time in GMT. One unit of trading volume is one million currency units. The ratio of absolute order imbalances to trading volumes is a proxy for the degree of informed traders' presence (Kaul, Lei, and Stoffman (2008)). The order imbalance is defined as the difference between buyer initiated deal volumes and seller initiated deal volumes. The price impact is defined as an absolute return over a unit of deal volumes. We calculated the averages of these variables across days.

Figure 2 about here

The pattern of intraday deal volumes is described in Figure 2.C. The plot exhibits spikes at the Tokyo fixing (GMT 00:55), US macro announcements (GMT 12:30), New York option cut (GMT 14:00), and the London fixing (GMT 15:00). As mentioned in introduction, although spikes in volume are remarkable and well-known, price behaviors during the two fixing windows have not been seriously analyzed. It will be shown that the patterns of price and liquidity in the two fixing windows differ from each other.

The ratio of absolute order imbalances to trading volumes is found to be high during the Tokyo market hours (Figure 2.A). It then remains low until it suddenly climbs up after GMT 20:00, when the New York market closes. Theoretically, this measure can be regarded as an indicator of privately informed trading (or PINs). Since traders are reluctant to trade with informed traders, this measure 
also indicates a degree of illiquidity of the market. Around fixings, the measure becomes low, potentially indicating high liquidity.

Order imbalances (OIB) typically concentrate around zero, but it jumps up to the positive around the Tokyo fixing (Figure 2.B). This is a unique feature of the Tokyo fixing. This effect of this imbalance to the prices is analyzed in section 5.2.

The price impact is low around fixings but high around announcements (Figure 2 D). After the New York market closes, the price impact significantly increases. Thus, as a measure of illiquidity, the price impacts are strongly correlated with the ratio of absolute order imbalances to trading volumes. While the results are omitted in this article, the bid-ask spread is also very tight around the fixings but wide around macro announcements.

\subsection{Intraday Pattern of Limit Order Book (LOB)}

The magnitude of a limit order book (LOB) reflects the activity of "firm quotes" of market participants that provide liquidity to the market. Large volumes of quotes (a thick book) would absorb large market-taker orders, thus reducing the transitory price fluctuations. In order to observe the behavior of liquidity providers around each event, we examine the intraday pattern of LOB.

In Figure 3, patterns of the limit order books are shown in three measures: (A) A natural log of the sum of bid and ask limit order volumes (up to four steps), (B) The imbalance between the bid and ask limit order volumes divided by the sum of total limit order volumes, $(\mathrm{C})$ the total number of the quote counts in each side of the book. Construction of the plot is as follows. Within every 60 seconds, we take the average of these variables. They are averaged across days for each 60 second window, providing the data for the plot.

Figure 3 about here

The sum of bid and ask limit order volumes, or the depth, is typically high during the time window when both London and New York markets are open (Figure 3.A). The quote count also has the similar pattern (Figure 3.C). The depth becomes particularly high during the fixings, but it becomes lower 
around the US macro announcement and NY option cut.

This pattern of depth indicates that traders behave more like a market maker during the fixing time while they tend to avoid the risk associated with potential surprise contained during macro announcements. In other words, when traders anticipate the price impacts around the fixing time, it is only transitory. The small price impact, as examined in the previous section, are consistent with this pattern of depth. ${ }^{14}$ The higher the depth becomes, the more difficult it becomes for traders to influence the prices, implying that frequent price spikes are less likely otherwise not intended. If traders intend to affect price, price spikes can happen even when much liquidity is supplied.

The depth does not have a particular intraday pattern except at the Tokyo fixing (Figure 3.B). The order imbalance around the Tokyo fixing is biased toward buying pressure of US dollar (Table 5). Because this temporal imbalance is commonly known, the depth is higher at the ask-side at the time of the Tokyo fixing, mitigating the price impacts from the imbalanced orders. Since the net buying pressure around the Tokyo fixing is typically observed every day, market participants provide liquidity to absorb the anticipated transitory price movement - yen depreciation. Without such traders, the market price would quickly deviate from the fundamental price. We note that this imbalance of order flows and limit orders happen only at the time of the Tokyo fixing of the USD/JPY pair. Around the London fixing, the depth increases, but there is no predictable imbalance of the depth. The imbalance of the LOB becomes volatile after the NY market closes (GMT 21:00 to 22:00), since the market becomes less active and the LOB becomes thin.

In this section, we examined the intraday pattern of the limit order book. In fact, much liquidity is provided around the fixing time than the other times, and this makes it difficult for a manipulator to influence the price. In this sense, markets tend to have a pressure towards the efficient market around the fixings. Imbalance of depth around the Tokyo fixing indicates that the excess of buying pressure is commonly known by market participants.

14 Except for during the New York option cut. This fact is somewhat puzzling. Potentially, the effect of 10AM macro announcement and the effect of option cut are mixed at this moment. 


\section{Three Empirical Puzzles}

Based on the institutional background and the intraday patterns, three puzzles about the Tokyo fixing emerge.

\subsection{Puzzle 1: Too frequent price spikes}

The first puzzle of the Tokyo fixing is that the trades concentrate in a few seconds around 00:55GMT (9:55 in Tokyo) with large transitory price spikes. We first examine the volume and liquidity pattern of 90 seconds around four volume spikes (Tokyo fixing, London fixing, US macro announcement, and NY option cut). Then we formally define the price spike. Finally we conduct regression-based analysis for the frequency of the spike in order to emphasize the frequency of spikes at the Tokyo fixing is unusual.

\subsubsection{Trading volume and liquidity of 90 seconds around volume spikes}

Figure 4 shows the pattern of trading volumes, the order imbalances, and the depth during a 90second period around the four events (i.e., 45 seconds before and after the point of event time), two of which are during fixing times. The depth is defined as the sums of the best ask and bid limit orders up to four steps. Each variable is averaged across days for each three-second window. The way of construction is the same as section 4.3. The currency pairs of EUR/JPY, EUR/USD, and USD/JPY are examined.

Figure 4 about here

Although each event is commonly associated with high trading volumes, their patterns are quite different. First, at Tokyo fixing, the high trading volume concentrates at GMT 00:55:00 (9:55am Tokyo time) and prior to the fixing, the depth gradually increases toward the time. After GMT 00:55:00, the depth suddenly drops, perhaps because the depth is consumed by the aggressive trades. The imbalance of order flows is pronounced at USD/JPY pair.

In contrast, for the London fixing, the trading volume has its first peak at 30 seconds before GMT 15:00:00, and it has another peak at GMT 15:00:00. After GMT 15:00:00, the trading volume gradually decreases. The depth shows a hump-shaped pattern. The order flow is balanced. 
US macro announcements and NY option cut times exhibit a similar pattern. The trading volume suddenly surge at the event time. But the limit orders are not large enough to cover the orders, which is the biggest difference from the patterns around fixing. The order flow is balanced.

The concentration of the trading volume is not usually observed in financial markets except for the needs of immediacy and the arrival of unanticipated content in news. Even when large volumes are to be traded, traders can avoid making price impacts by splitting the large trade if they have enough time to trade. During the fixing period, much liquidity is provided and the banks have time to trade for a one-minute window. Moreover, at the moment of fixing, the large transaction volume is induced not because of the arrival of news but because of the temporal imbalance of supply and demand of currency. In fact, at the moment of London fixing, the orders are dispersed over the one-minute fixing windows, indicating that the traders try to split their orders for minimizing the price impacts and for taking the closer prices to the fixing. Thus, the unusual concentration of trading volume at the Tokyo fixing invokes a suspicion that the large transaction and associated volatility in prices are intended.

The unusual pattern of transaction volumes with price volatility despite a large pool of liquidity, as shown above, is a puzzle. In order to measure the degree of price volatility, we define a transitory jump of the price (we call it a spike), and carry out a statistical analysis on the frequency of spikes.

A “price spike,” an unconventional measure of price movement, is defined to emphasize the unique pattern of price movements at the time of the Tokyo fixing. The transactions and price movements at the time of the fixing window is less likely to induce a permanent change in the foreign exchange rate, unlike a macroeconomic announcement. Prices and volumes during the fixing window only represents the temporary imbalance of liquidity. Hence the increase in price is expected to be followed by the decline. Although transitory price spikes have caught little attention from academics, they are practically important because they relate to predatory trading (Brunnermeier and Pedersen (2005)). Particularly in the Tokyo fixing, retail customers' orders will be traded at the fixing price the bank sets itself, based on the transactions during the fixing time window. The price can be the most favorable to banks and the least favorable to retail clients. Whether the prices tend to have spikes or 
not can be a big concern for both the banks and the clients.

\subsubsection{Definitions: Spikes and major price shocks}

Since the large number of spikes is naturally associated with large transaction volumes, we need a way to normalize them. For this purpose, we also define "major price shock" as a big price change for normalizing the number of spikes. The frequent spikes indicate that the transactions do not contribute to the price discovery, and the transactions are more likely related to the manipulative trades (as indicated by Brunnermeier and Pedersen (2005)) and the imbalance of short-term supply and the demand of the currency.

In order to construct the data of spikes and major price shocks for each currency pair, we first calculate the X-second return from the EBS transaction data. ${ }^{15}$ A return at time $t$ can be followed by the time $t+1$ return in either direction: (1) the time $t+1$ returns in the same direction (or zero return), and (2) the opposite direction, namely a reversal. In the second case, the movement of price at $t$ is only transitory. In order to avoid the bid-ask bounce, we focus on the case where the price change is extremely large and call them a "spike”. The detailed procedure of constructing spikes and major price shocks is described as follows:

- Calculate X-second returns.

- Define a "reversal" at $t$ for all samples as an observation where the return from $t-1$ to $t$ is followed by a return from $t$ to $t+1$ in an opposite direction with a magnitude of more than $80 \%$ of the return between $t$ and $t-1$.

- Omit zero returns. Rank returns of all samples from the largest (positive) to the smallest (negative). Extract the observations from the top 5\% and the bottom 5\%. The extracted observations are defined as major price shocks. If an observation has the "reversal" feature, it

15 For calculating the return from transaction price, we use the last transaction in each interval. If we set $\mathrm{X}=10$ and there is no trade during the ten seconds, we refer to the last transaction. Since the transaction is irregular, the interval of return is not exactly equal to ten seconds, but at least a minimum of ten seconds. 
is defined as a spike.

- Thus, major price shocks include spikes.

We count the number of spikes and major price shocks in a Y-minute window. ${ }^{16}$ For this construction, the number of major price shocks relative to the number of deals do not change much across currency pairs. The basis point (bp) size of the extracting point (i.e., $5 \%$ top and bottom) depends on the sampling frequency of $\mathrm{X}$. For the case of $\mathrm{X}$ being one second, low liquidity currencies such as AUD/USD, EUR/GBP, GBP/USD, USD/CAD typically have the extracting point of 4bp to 6bp, while high liquidity currencies such as EUR/JPY, EUR/USD, USD/CHF, USD/JPY have the extracting point of $1.2 \mathrm{bp}$ to $2.2 \mathrm{bp}$.

In the following analysis, we set $\mathrm{X}$ as one second, and $\mathrm{Y}$ as fifteen seconds or one minute unless otherwise noted. Overall, results are not affected by the small changes in the sampling frequency.

Although the definition of spikes above aims to capture the transitory price shocks rather than permanent, it potentially includes the situation that transitory changes accumulate to be a permanent change. For example, many spikes which have $80 \%$ reversals could cumulatively result in an increase over the fixing window. For checking the robustness of this definition, we defined two other definitions of spikes. The details of the construction of the measure and the results are found in the Internet Appendix of this paper. The results in this paper are robust to the changes in the definition of spikes.

Table 2 shows the relative frequency of spikes per one minute in specific intraday period and sampling periods. We focus on EUR/USD and USD/JPY. Overall, the spikes tend to occur within and around both fixing periods. For the one minute window of the Tokyo fixing (USD/JPY), one spike is likely every four days $(1 / 0.247=4.04)$, and for the one minute window of the London fixing (USD/JPY), one spike is likely every 6.5 days $(1 / 0.153=6.5)$. Both frequencies are much higher than those of the whole sample. The spikes are even more likely at particular days such as the end of

16 For aggregating one minute around the time of $\mathrm{Z}$, we usually start sampling 30 seconds before $\mathrm{Z}$ and end sampling 29 seconds after $\mathrm{Z}$. 
month, Friday, and the $5^{\text {th }}$ and $10^{\text {th }}$ days of the month. In 2008 and 2009, there were a larger number of spikes than in other years. Although these descriptive statistics show apparent increases of spikes around the fixings, the size of deals associated with the fixing should be controlled, which will be done in the following sections.

\section{Table 2 about here}

\subsubsection{Intraday Seasonality of Spikes}

The intraday pattern of spikes are shown in Figure 5. In this analysis, we focus on the USD/JPY because they typically have high volumes in the two fixings.

Because the frequency of spikes is usually correlated with high trading volumes in a time window, we need to normalize the variable. ${ }^{17}$ We also examine the normalization by the number of major price shocks. This normalization captures how likely large movements end up with transitory price changes (i.e., spikes).

The frequency of spikes and major price shocks (in the common logarithm) is described in Figure 5.A. Figure 5.B and Figure 5.C show the frequency of spikes divided by the major price shocks (B) and the frequency of deals (C). Figure 5.D shows the difference between the frequency of positive spikes and the frequency of negative spikes. For the calculation, the sample is from the days that both the US and UK are under daylight saving time. Each variable is averaged across days for every 60 seconds (here we take $\mathrm{Y}=60$ seconds). ${ }^{18}$

Figure 5 about here

Spikes can be more frequent during the Tokyo fixing time (Figure 5.A) than at any other times. A spike can occur roughly once in every ten days. The spike to major price shock ratio is also high

17 A natural candidate for the normalization is using the frequency of trades. For this normalization method, however, the number of spikes can be underestimated because of the many small trades.

18 Note that we set a 15-second interval for Figure 5, but we set one minute interval for Table 2. For this reason, the presented figures are not necessarily the same. 
during the fixing, while the spike to trade ratio is not particularly high (Figure 5.B and C). ${ }^{19}$ After normalizations, the spikes at London fixing are no longer observable. What is unique about the Tokyo fixing is that positive spikes are much more likely (Figure 5.D). The significance of these results are found in the Internet Appendix.

\subsubsection{Regression analysis for the frequency of spikes}

Lastly, we conduct a regression analysis for the frequency of spikes on the event dummies. This analysis is for controlling the trading activities such as trade frequencies and depths.

We take the frequency of spikes as dependent variables. The sampling frequency of the variable is by one minute. ${ }^{20}$

Independent variables are dummies for the four events. Each event has three dummies that indicate 30 seconds before and after the event time, 10 minutes before and after the event time.

Our interest is in the effect of time dummies on the frequency of spikes. For this aim, we control for the effect of the one minute trade frequencies, trade size, the market price-VWAP gap, Friday, and end-of-month dummy. We also control for the effect regarding the limit order book: the bid-ask spread, the depth, and the quote count. Since the sample includes the decimalized period, we conduct the regression separately for before the decimalized period, decimalized period, and half-pip period. In this article, we present only the results for before the decimalized period for the sake of brevity.

Since the dependent variable is count data, we conduct negative binomial regression for the count of the spikes. We also attempt a least-square method by using a two-stage least square (TSLS). The overall results are the same and we also do not report the results using the least-square method for the same reason above.

19 Under the mechanism of the Tokyo fixing, the banks may be satisfied with one spike of the transaction price for their purpose of posting its biased fixing price, and our measure to capture the count of spikes may not be appropriate. This is probably one reason why the method of normalization is important for the count of spikes.

20 That is, we set $Y=$ one minute and calculate the number of spikes from -30 to 30 seconds for each minute. 
Our sample ranges from January 5, 2006 to December 31, 2013. The sample period before the decimalization is January 5, 2006 to March 6, 2011. The currency pairs are EUR/JPY, EUR/USD, USD/CHF, and USD/JPY. Each variable is constructed as one-minute time aggregated variables. The trading volume is the sum of total trading volumes during each minute, and the trade size, bid-ask spreads, depth, quote count, and VWAP are the average during each minute.

Table 3 shows the estimation results. Overall, each currency has similar results for the frequency of spikes, while there is little observable pattern for the results of the average-median gap. Trade controls and LOB controls have intuitive results; larger trading volumes tend to associate with many price spikes. When the liquidity is low, that is, the bid-ask spread is high, the depth is low, and the quote count is low, then the spikes become more frequent.

Table 3 about here

Our regression analysis confirms the existence of frequent spikes at the moment of the Tokyo fixing. The dummy of the Tokyo fixing (labeled as “j0055”) becomes positive and statistically significant, which is common across currency pairs. This is robust to the changes in the definition of spikes (the results presented in the Internet Appendix). This result makes a clear contrast from that for London fixing dummy (“j1500”) which does not positively affect the frequent spikes.

Thus, our analysis suggests frequent spikes at the Tokyo fixing time. As already explained, these frequent spikes do not necessarily indicate inappropriate behavior of the banks, because the banks can set their own fixing rates within the range that they have made a transaction. In that sense, they are allowed to do this for the purpose of hedging. The bank's profitability is subject to changes in the exchange rate after the fixing is done.

\subsubsection{Robustness of the analysis}

In addition to the regression analysis above, we also applied the same regression framework to the different definition of spikes: spikes defined by the one-second negative correlation and the max-min price gaps within fixed time intervals. For the first definition, the dependent variable is the frequency of spikes, the same as our original definitions, and we can apply the same methodology. For the 
second definition, the dependent variable is a binary dummy which indicates the presence of a spike within the fixed time interval. We use a logit model for this case.

The results are robust for the changes in the estimation methodology and the definition of spikes. In the Internet Appendix, we conduct the similar regression analysis for the different definitions of spikes. Again, the coefficients for the dummy for the one minute window within the London fixing is not significantly positive. We do not find the evidence that the spikes at the London fixing are particular frequent after controlling for the market situations.

\subsection{Puzzle 2: Predictable pattern of the orders and price (Table 4)}

The second puzzle is the predictable pattern of orders and price around the fixing. On average, there are more buying orders before the fixing which push up the price of foreign currency (USD and EUR). The pattern can be found in Figure 2. In this section, we examine this fact further.

The frequency of spikes can capture the transitory price changes in a few seconds, and they cannot capture more gradual return reversal of prices. The traders in banks, however, typically start trades for fixing before the fixing windows. This behavior is called pre-hedging. Evans (2014) finds the negative correlation between the return before and after the London $4 \mathrm{pm}$ fixing. Following this, as a first examination, we calculate the correlation between returns before and after events. If there could be a return reversal, we would observe the negative correlation of returns. Positive correlation indicates a momentum of the price after the event. Under the hypothesis of the efficient market, the correlations should be zero.

Table 4 tabulates the Spearman's correlation of coefficients of the returns for each currency pair. We change the intervals to calculate the return from one minute to thirty minutes. We also tested the pattern on Friday and at the end of month when settlement needs are expected to be higher than other days. $^{21}$

21 The sample size of the end of month is small. Evans (2014) used empirical distribution to deal with this problem and also reported the abnormality of the pattern of return around the London fixing at the end of month. 
Table 4 about here

While return reversals are reported at the London fixing (Melvin and Prins (2015), Evans (2014)), they are not found at the Tokyo fixing (Table 4). The signs of the correlation are not consistent.

This result of no negative correlation, however, does not necessarily indicate there is no predictability around the Tokyo fixing. Rather, USD and EUR tend to appreciate toward the fixing on average because of the buying pressure on the foreign currencies. For examining this, we calculated the average return of the investment incurred by holding the USD/JPY long for five minutes and then shorting it for the following five minutes. The results are illustrated in Figure 6.

Figure 6 about here

The horizontal line is a GMT time when the long position and the short position switches. The return is calculated by the transaction price. For 15 years of this simple strategy, if the switching time is at the moment of the Tokyo fixing (00:55GMT), the average return becomes $1.8 \mathrm{bp}$. This return is slightly above the transaction cost from the bid-ask spread. The top panel shows that this abnormal return is very distinct from those of any other time of day. The top and bottom 1\% of the returns are truncated, and the results are not driven by outliers. Also, as we have already examined, there is much liquidity available at this time. Lack of liquidity does not explain this return. In the bottom panel, we show that the return becomes particularly high at 5th and 10th days (except for the days close to the end of month), and the 31st day of month or the end of month. Thus, the excess of buying pressures produces a very abnormal pattern of prices around the Tokyo fixing.

\subsection{Puzzle 3: Deviation of announced fix rate from the market prices}

The third puzzle is that fixing rates announced by each bank deviate from the transaction prices observed in market data. In other words, banks may impose additional implicit costs on retail customers by announcing the fixing rate that does not represent actual trade.

Unlike the London fixing, there are multiple Tokyo fixing prices. Each bank sets its own fixing price and the fixing prices differ among major banks. For each bank, it is a business decision to set its own fixing rate. Theoretically, a bank could execute in the fixing window all the orders it received 
before the fixing time, and then announce the fixing rate that is the median of its transactions. Then the bank would break even in executing retail orders, except they can still charge the bid-ask spread to retail customers. If this is the case, the fixing price set by the bank should be close to the median transaction price during the fixing window.

A reasonably long time-series on the daily fixing rate is available, on its web site, from each of two banks, the Bank of Tokyo UFJ (BTMU) and Mizuho Bank. The fixing window is defined as one minute window from GMT 00:55:00 to GMT 00:55:59. We checked two definitions for the market rate that replicate the fixing rate: maximum and median transaction prices during the fixing window. We take the maximum price, not a minimum, because, as we explained earlier, there are order imbalances of more buying USD than selling orders around the Tokyo fixing time. The log differences of the two prices are multiplied by 10000.

In order to remove short-term fluctuations, the 30-day moving averages of the fixing-max gap (fixing-median gap) are shown in Figure 7 (panel A, panel B). Summary statistics are presented in Table 6.

Figure 7 about here

Table 6 about here

To quote the fixing price above the maximum of the actual transaction prices during the fixing window means that the bank was able to reap the extra profits by the price that was not supported by the actual trade. Evidently, the gaps were positive before November 2008 at the early stage of the Global Financial Crisis. That is, the banks used to set the fixing rate higher than the maximum market rates by around 2.5 bp during this period. The higher fixing rate is set to be in favor of the bank's position when they have more retail orders buying than selling at the fixing price, which is usually the case in the Tokyo market.

These gaps are common across banks. The two banks tend to submit fixing rates similar to each other. The correlation of the fixing-max gaps of the two banks was $80 \%$ before 2008, but it has fallen to less than $50 \%$ after 2008 . The level of the gaps are close to the US-Japan interest rate differentials. 
Is it possible to support the deviation of the rates? A possible explanation is the swap point due to the overnight interest rate differentials. ${ }^{22}$ The bank completes the customer transactions at $t=0$, while the settlement of the interbank market is $t=2$. When the bank executes the purchase of the dollar order from the customer, it has to borrow the dollar for two days. The swap points for borrowing the dollar against the yen for two days is twice the overnight interest rate differential between the dollar and the yen. The bank seems to charge the interest rate differential to the customer as a surcharge on the fixing rate, since the coefficient of the interest rate is significant. ${ }^{23}$ In fact, the difference between the fixing rate and the average (or max) of the trading rate during the fixing window has a strong correlation with the interest rate difference between the interbank overnight rates in the US and Japan. For the US overnight rate, the Federal Funds rate is used in the US and the uncollateralized call rate is used in Japan. Both variables take large values in the period from 1999 to 2001 and from 2005 to 2008. As shown, there are consistent order imbalances for the US dollar. That explains the positive correlation between the fixing rate gaps and the interest rate differentials.

Although the level of the fixing rate gaps are well explained by the swap point, daily fluctuations of the gaps still exist. Since the fixing rate set by the bank is valid throughout the business hours in Tokyo, the bank has to hedge against the adverse movement of the exchange rate for the rest of the day. This is in contrast to London, where the fixing (or market clearing) is done at the end of business hours. Here, fixing is done in the first hour of business hours. Although Japanese banks set a wide bidask spread for retail customers, a competing bank may set a slightly different rate to steal businesses. The bank can set the fixing rate different than the median price to earn an extra profit to cover possible losses from the rest of the day.

To analyze the pattern of the gap, we conduct the following regression analysis.

22 We appreciate a seminar participant in JSME for pointing this explanation.

23 This implicit swap point is not imposed in WM/Reuters fixing rate, although the process of settlement follows the same. 


$$
\begin{gathered}
\log \left(\text { Fix }_{d}\right)-\log \left(P_{d}\right)=\alpha \\
+\beta_{1} \text { Before. volatilit } y_{d}+\beta_{2} \text { Before. OIB } B_{d}+\beta_{3} \text { Before.cumRet }_{d} \\
+\beta_{4}\left(\log \left(P_{d}\right)-\log \left(V W A P_{d}\right)\right)+\beta_{5}\left(\log \left(F i x_{d-1}\right)-\log \left(P_{d-1}\right)\right) \\
+\beta_{6} \text { Interest rate differential }+ \text { Dummies }+\epsilon_{d}
\end{gathered}
$$

The frequency of the observation is daily, which is denoted by the subscript " $d$ ". The data for the BTMU are available since 1999, and for the Mizuho since 2002. The dependent variable is the difference of the log between the fixing prices for the BTMU or the Mizuho bank $\left(\mathrm{Fix}_{d}\right)$ and the maximum of the transaction prices during the fixing window $\left(\mathrm{P}_{d}\right)$. We take the "max" of the transaction price during the fixing, or 60 seconds from JST 9:55 am (GMT 00:55), because banks have incentives to announce the maximum price during the fixing window as a fixing price of the day, since that would maximize banks' profits when there is an order imbalance toward buying foreign currencies. Since the transaction at the Tokyo fixing is concentrated in USD/JPY, our analysis is reported only on the USD/JPY.

The independent variables are: one minute return volatility, the sum of the order imbalance (OIB), cumulative returns, gaps between the $\log$ prices of $\mathrm{P}_{d}$ and the volume weighted average price (VWAP), a lag of the independent variable, US-Japan interest rate differentials, and the calendar dummies. $^{24}$ The volatility, OIB, and cumulative returns are calculated from the sample from 9:00 JST to 9:54 JST. The calendar dummies are dated on the $5^{\text {th }}$ and $10^{\text {th }}$ days, Friday, and the last trading day of each month. The standard errors are corrected by the Newey-West method. The results are shown in Table 5.

\section{Table 5 about here}

Although the t-statistic of the coefficient on the interest rate differential is the largest, the other coefficients are still significant. The fixing rate tends to become high (or the yen depreciates) in the following situations: (1) when aggressive orders between 9:00 JST and 9:54 JST depreciate the yen, (2) when the market rates become higher than the volume weighted average price (VWAP), i.e. when the market price temporarily deviates from the trader's average purchasing prices, (3) on the $5^{\text {th }}$ and

${ }^{24}$ The VWAP is widely used as a reference of market price. The deviation of prices from VWAP indicates unusually high price pressures at the moment. 
$10^{\text {th }}$ days and Friday, and (4) when the return volatility is low. Coefficients of these factors are statistically significant at a 1\% level for both banks and currencies.

Each coefficient shows how they influence the incentive of banks to setting more profitable fixing rates. The positive coefficient of the order imbalance suggests that some market participants purchase the foreign currency even before the fixing when the fixing rate is expected to become high. Potentially banks may purchase the currency to hedge the risk of fixing determination. Since the dummies for the $5^{\text {th }}$ and $10^{\text {th }}$ days and Friday, or indicators of high settlement needs by clients, are positive and significant, banks may respond to the client's demand and set higher fixing rates.

One way to interpret the coefficient of VWAP is that it reflects the large needs for foreign currencies on the day when traditionally settlements are concentrated. In fact, order imbalances before the Tokyo fixing time tend to be high (Figure 4), which may cause the deviation of market price from the VWAP. When the order imbalance is particularly high, the fixing rate has an upward bias.

It is hard to interpret the coefficient on volatility. The banks may set large gaps, or premiums, to avoid the risk of intraday price fluctuation. Thus the coefficient on volatility is expected to be positive, but the estimated value is significantly negative.

These estimation results are similar for the two banks and for the two currency pairs. The coefficients on the interest rate differentials are close to one. Even when the dependent variable is replaced with fixing rate $-\frac{2}{250} \times$ interest rate differentials, the qualitative results for other coefficients remain the same.

Our findings for the Tokyo fixing are summarized as follows. (1) Price spikes in the Tokyo fixing are more frequent than in the London fixing. (2) The customer orders are biased toward buying the foreign currencies, which is predictable. (3) Before 2008, the fixing prices set by banks were biased upward, and higher than the highest transaction price during the fixing time window. (4) Even after 2008, the fixing prices announced by banks were still above the median transaction price during the fixing window, suggesting that banks make predictable profits. (5) The calendar effects also matter for determination of the fixing rate and the price fluctuation around fixing time. 


\section{Conclusion and Discussion}

In this paper, we find three puzzles regarding Tokyo fixing: At the moment of Tokyo fixing (or 9:55 JST), there are a tremendous amount of deals which are not observed in the other minute of the trading day, inducing frequent transitory price spikes (Puzzle 1). Also, the direction of the spike and orders before the fixing incline toward buying, producing predictable price patterns around the fixing time (Puzzle 2). Lastly, the banks had announced a biased fixing rate before 2008, which is not necessarily based on the transactions in the EBS market (Puzzle 3). These puzzles contradict to the efficient market hypothesis.

Why Tokyo fixing has so many puzzles? The first clue to solve the puzzles is the persistent order imbalances. Why are there steady imbalances of buying foreign currency before the fixing? As the actual demand from retail customers, only importers ask banks to purchase dollars for them. Then, why importers prefer to settle trades at the fixing, while exporters do not? These preferences reflect differences in the sophistication of managing currency risk between importer and exporters. In the long history of continuously appreciating yen, Japanese exporters have developed various ways of hedging currency risks. For example, some companies concentrate on currency risk management of the group in a currency layover entity, which makes the buy-sell limit orders depend on market conditions. They do not usually ask banks for deals at the fixing rate. Japanese large importers such as electric power companies, in contrast, do not pay much attention to the intraday changes of the exchange rate, since any cost increase can be passed on to consumers. They typically ask banks to settle the trades at the fixing rates. Such difference in behaviors of Japanese industries is said to be the cause of the imbalance of orders for the Tokyo fixing time. The concentrated excess demand for dollars enable Japanese banks to be able to extract information from their own order imbalances.

The second clue is the microstructure; the bank can set its own fixing price within the range that it made transactions in during the fixing window. (This limitation was not even present before 2008.) Thus, banks have an incentive to make transactions at a very extreme price recorded during the fixing 
time window, which can be applied to the fixing rate for the transaction between the bank and its retail customers.

When a large bank is certain that order imbalances exist, it can use two tactics to increase profits. First, it has an incentive to front-run the orders to keep the inventory cost down. Second, it welcomes volatility during the fixing time window. When it has a wide range of transaction prices during the fixing time window, the bank can pick a profit-maximizing fixing price. When there exists an excess demand for dollars, the bank attempts to drive up the price to make evidence of transaction record. That gives legitimacy for posting the high (appreciated dollar) fixing price. Thus, the retail customers' excess demand is executed at the high spread between the fixing price and the average inventory price. This behavior solves puzzles 1 and 2 .

There is a limit to how high the fixing rate could be. The banks do compete with other banks for the fixing prices. This competition can reduce the rent of banks by setting an unfavorable rate for retail customers. Since the fixing rate is applicable even after 10 am until the end of Tokyo business hours, the bank quoting out of line fixing price may expose itself to unbalanced orders after 10 am. Retail customers who seek to buy may choose the bank that posts the cheapest fixing rate. Moreover, the deviation of one bank's fixing price from others may prompt arbitrage transactions targeted to banks. Therefore the deviations among banks idiosyncratic fixing rates have natural limits, though the deviation does persist. In Japan, large companies tend to have "main banks" for their overall financial services; foreign exchange services are only one aspect of the bank-firm relationship. Unless the deviation of fixing prices is not very wide, the large firm stays with the main bank. Moreover, Forex transactions had been dominated by the Bank of Tokyo, which later merged with Mitsubishi Bank, for a long time, and the fixing rate of each bank tends to be similar even now, weakening the incentive for clients to switch to an alternative bank for Forex transactions. ${ }^{25}$

25 The Bank of Tokyo merged with Mitsubishi bank in 1996. The merged bank, the Bank of Tokyo-Mitsubishi, again merged with the UFJ bank to become the Bank of Tokyo-Mitsubishi UFJ in January 2006. 
In summary, the apparent puzzles are solved by these two factors: (1) the difference between large importers' behavior and large exporters' behavior, and (2) the microstructure of the Tokyo fixing practice (namely an individual bank announces its own fixing rate). The econometric analysis of the tick-by-tick data firmly established that the banks’ fixing price-setting depends on the order imbalances. That is, the larger the order imbalances, the larger will be the spread (or profit margin) between the fixing price and the market average/median price. The spread is particularly wider when there are large needs from real-side demands like $5^{\text {th }}$ and $10^{\text {th }}$ days of the month. The evidence does not point to any collusive behavior among Japanese banks, unlike the collusion that was found among London banks in the WM/Reuters scandal. However, it does point to unsophisticated importers in the regulated industry, where increased costs can be passed on to the users of energy products and services, and banks can engage in monopolistic behavior, taking advantage of captive retail customers. 


\section{References}

Andersen, Torben G., Tim Bollerslev, Francis X. Diebold, and Clara Vega, 2003, Micro effects of macro announcements: Real-time price discovery in foreign exchange, The American Economic Review 93, 38-62.

Brunnermeier, Markus K., and Lasse Heje Pedersen, 2005, Predatory trading, Journal of Finance 60, 1825-1863.

Cameron, A Colin, and Frank A G Windmeijer, 1996, R-Squared measures for count data regression models with applications to health care utilization, Journal of Business \& Economic Statistics 14, 209-220.

Chaboud, Alain P, Sergey V Chernenko, Edward Howorka, Raj S Krishnasami Iyer, David Liu, and Jonathan H. Wright, 2004, The high-frequency effects of US macroeconomic data releases on prices and trading activity in the global interdealer foreign exchange market, Board of Governors of the Federal Reserve System International Finance Discussion Papers.

Evans, Martin D D., 2014, Forex Trading and the WMR Fix, Working Paper.

Evans, Martin D D., and Richard K. Lyons, 1999, Order flow and exchange rate dynamics, Journal of Political Economy 110, 170-180.

Evans, Martin D.D., and Richard K. Lyons, 2008, How is macro news transmitted to exchange rates?, Journal of Financial Economics 88, 26-50.

Hashimoto, Yuko, and Takatoshi Ito, 2010, Effects of Japanese macroeconomic statistic announcements on the dollar/yen exchange rate: High-resolution picture, Journal of the Japanese and International Economies 24, 334-354.

Ito, Takatoshi, Richard K. Lyons, and Michael T. Melvin, 2002, Is there private information in the FX market? The Tokyo experiment, Journal of Finance 53, 1111-1130.

Kaul, Gautam, Qin Lei, and Noah Stoffman, 2008, Aiming at Pin: Order Flow, Information, and Liquidity, Working paper.

Kyle, Albert S., 1985, Continuous auctions and insider trading, Econometrica 53, 1315-1335.

Melvin, Michael, and John Prins, 2015, Equity hedging and exchange rates at the London 4p.m. fix, Journal of Financial Markets 22, 50-72.

Ni, Sophie Xiaoyan, Neil D. Pearson, and Allen M. Poteshman, 2005, Stock price clustering on option expiration dates, Journal of Financial Economics 78, 49-87. 
Table 1: Timeline of events in the Forex market

\begin{tabular}{|c|c|c|c|c|c|c|c|c|}
\hline \multirow[b]{2}{*}{ GMT } & \multicolumn{3}{|c|}{ Winter time } & \multicolumn{2}{|c|}{ Summer time } & \multirow[b]{2}{*}{ JST } & \multirow[b]{2}{*}{ EVENT } & \multirow[b]{2}{*}{ Major Announcements } \\
\hline & $\mathrm{LN}$ & EST & JST & $\mathrm{LN}$ & EDT & & & \\
\hline $0: 00$ & $0: 00$ & 19:00 & $9: 00$ & $1: 00$ & $20: 00$ & $9: 00$ & Tokyo open & \\
\hline & & & & & & & Tokyo Fixing & \\
\hline $1: 00$ & $1: 00$ & $20: 00$ & $10: 00$ & $2: 00$ & 21:00 & $10: 00$ & $(9: 55)$ & Australia: statistics (GMT1:30) ${ }^{26}$ \\
\hline $2: 00$ & $2: 00$ & $21: 00$ & $11: 00$ & $3: 00$ & 22:00 & $11: 00$ & & \\
\hline $3: 00$ & $3: 00$ & $22: 00$ & $12: 00$ & $4: 00$ & 23:00 & $12: 00$ & & Japan: monetary policy announcement \\
\hline $4: 00$ & $4: 00$ & 23:00 & $13: 00$ & $5: 00$ & $0: 00$ & $13: 00$ & & RBA policy rate (GMT4:30) \\
\hline $5: 00$ & $5: 00$ & $0: 00$ & $14: 00$ & $6: 00$ & $1: 00$ & $14: 00$ & & \\
\hline $6: 00$ & $6: 00$ & $1: 00$ & $15: 00$ & $7: 00$ & $2: 00$ & $15: 00$ & Tokyo option cut & \\
\hline $7: 00$ & $7: 00$ & $2: 00$ & $16: 00$ & $8: 00$ & $3: 00$ & $16: 00$ & & Switzerland: policy rate and statistics ${ }^{27}$ \\
\hline 8:00 & 8:00 & $3: 00$ & $17: 00$ & $9: 00$ & $4: 00$ & $17: 00$ & London open & \\
\hline 9:00 & 9:00 & $4: 00$ & $18: 00$ & $10: 00$ & $5: 00$ & 18:00 & & UK: statistics (BST10:30) ${ }^{28}$ \\
\hline $10: 00$ & $10: 00$ & $5: 00$ & 19:00 & $11: 00$ & $6: 00$ & $19: 00$ & & \\
\hline $11: 00$ & $11: 00$ & $6: 00$ & 20:00 & $12: 00$ & $7: 00$ & 20:00 & & \\
\hline $12: 00$ & $12: 00$ & $7: 00$ & 21:00 & $13: 00$ & 8:00 & $21: 00$ & & $\begin{array}{l}\text { UK: policy rate, ECB policy rate (GMT } \\
12: 45)\end{array}$ \\
\hline $13: 00$ & $13: 00$ & $8: 00$ & $22: 00$ & $14: 00$ & $9: 00$ & $22: 00$ & NY open & $\begin{array}{l}\text { US (EDT8:30) })^{29} \text { and Canada } \\
\text { (GMT12:00 and 12:30) }{ }^{30} \text { statistics } \\
\text { US (EDT10:00) macro indicator }{ }^{31} \text {, }\end{array}$ \\
\hline $14: 00$ & $14: 00$ & $9: 00$ & 23:00 & $15: 00$ & $10: 00$ & 23:00 & NY Option cut & Canada: policy rate (GMT 14:00) \\
\hline $15: 00$ & $15: 00$ & $10: 00$ & $0: 00$ & $16: 00$ & 11:00 & 0:00 & London Fixing & \\
\hline $16: 00$ & $16: 00$ & $11: 00$ & $1: 00$ & $17: 00$ & $12: 00$ & $1: 00$ & & \\
\hline $17: 00$ & $17: 00$ & $12: 00$ & $2: 00$ & 18:00 & 13:00 & $2: 00$ & & \\
\hline $18: 00$ & 18:00 & $13: 00$ & $3: 00$ & 19:00 & $14: 00$ & $3: 00$ & & $\begin{array}{l}\text { FOMC policy announcement and } \\
\text { minutes (EDT 14:00 or 14:15) }\end{array}$ \\
\hline $19: 00$ & 19:00 & $14: 00$ & $4: 00$ & $20: 00$ & $15: 00$ & 4:00 & & \\
\hline 20:00 & $20: 00$ & $15: 00$ & $5: 00$ & 21:00 & $16: 00$ & 5:00 & NY Close & \\
\hline $21: 00$ & $21: 00$ & $16: 00$ & $6: 00$ & 22:00 & $17: 00$ & $6: 00$ & & \\
\hline $22: 00$ & 22:00 & $17: 00$ & $7: 00$ & 23:00 & 18:00 & $7: 00$ & & \\
\hline 23:00 & 23:00 & 18:00 & 8:00 & $0: 00$ & 19:00 & 8:00 & & Japan: statistics (JST 8:30 and 8:50) ${ }^{32}$ \\
\hline
\end{tabular}

26 Unemployment statistics, Retail sales, CPI, Trade balance, GDP.

27 Retail sales (GMT 7:15), CPI (GMT 7:15). GDP (GMT 5:45), Unemployment rate (5:45), Trade balance (GMT 6:00).

28 BOE inflation report, Unemployment statistics, Monetary policy committee, Retail sales, GDP, Trade balance)

29 Unemployment statistics, ADP unemployment statistics (EDT8:15), Unemployment insurance claim, Retail sales, CPI, Trade balance, GDP.

30 Unemployment statistics and CPI (GMT 12:00). Retail sales, Manufacture's sales, GDP (GMT 12:30)

31 US macro indicator: e.g., Business Inventories, Construction Spending, Consumer Confidence, Existing Home Sales, Factory Orders, IBD/TIPP Economic Optimism, ISM Manufacturing, U. of Mich. Sentiment, and Wholesale Inventories.

32 Unemployment statistics, CPI at JST 8:30. Machinery orders, GDP, Trade balance at JST 8:50. 


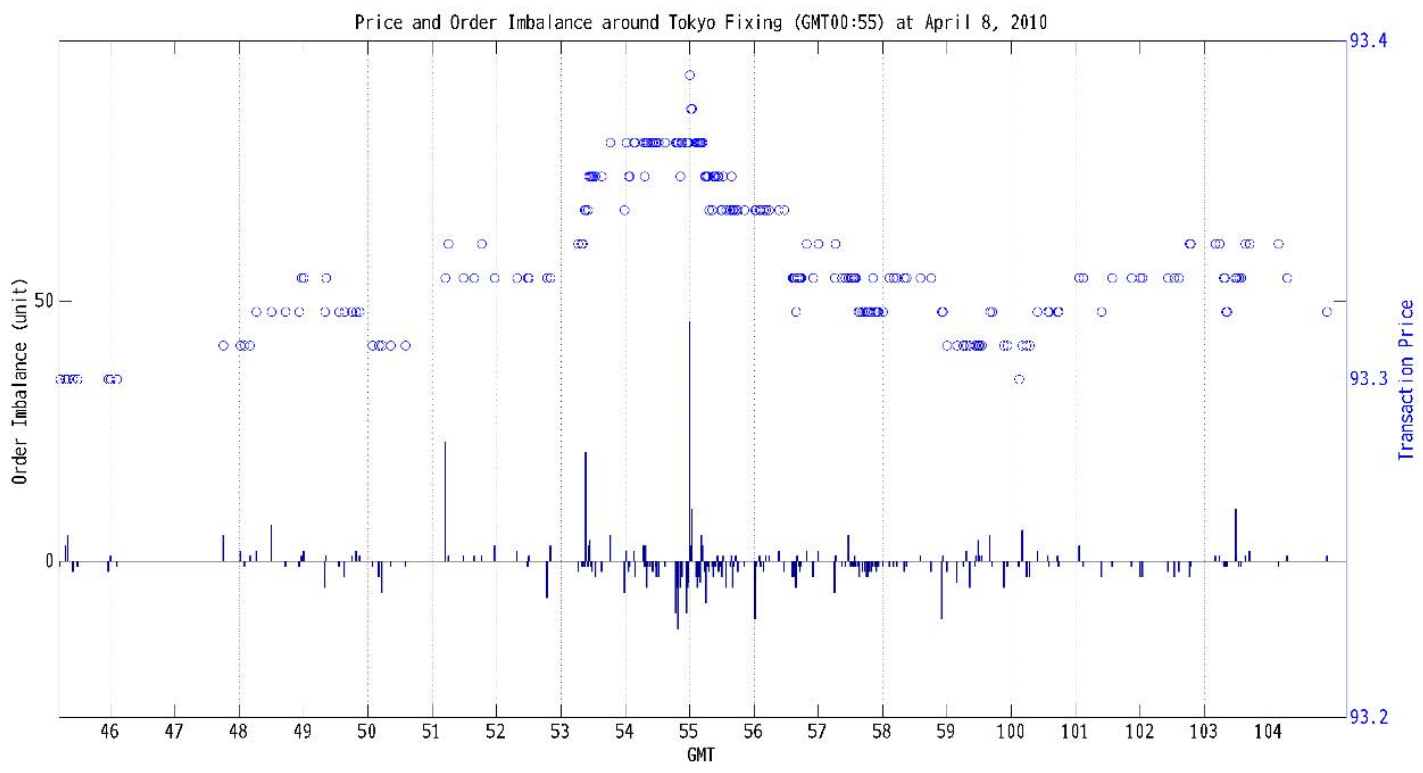

Figure 1: Example of observed spikes around Tokyo fixing

This figure presents the observed spikes around Tokyo fixings for USD/JPY (April 8, 2010). The horizontal axis is GMT and the vertical axis is either the order imbalance (bar chart) or transaction price (circle plot). 


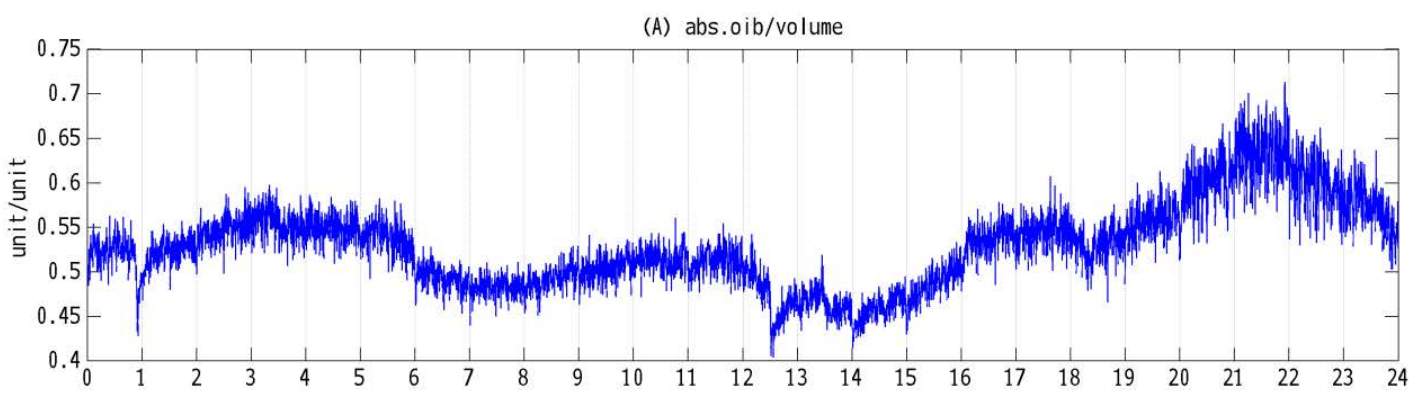

(B) oib

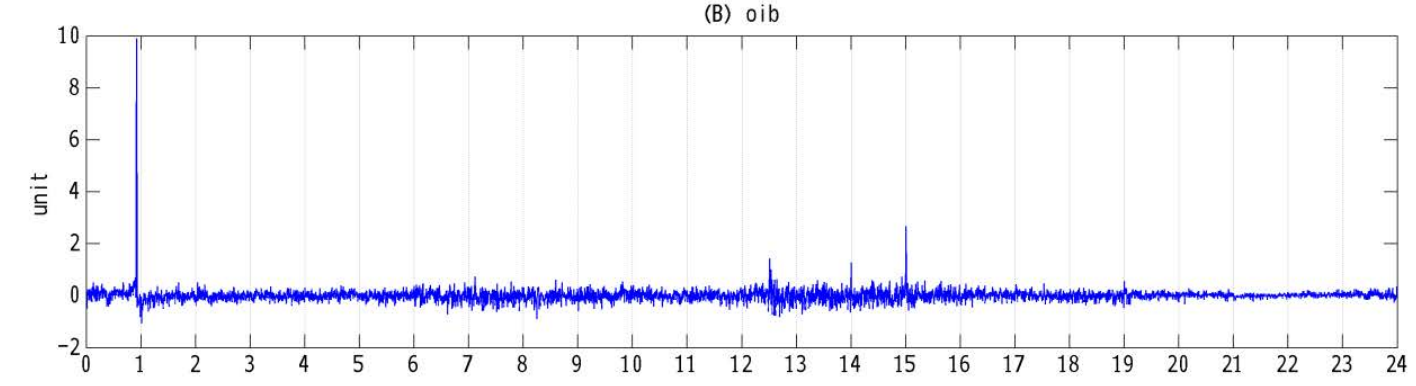

(C) volume
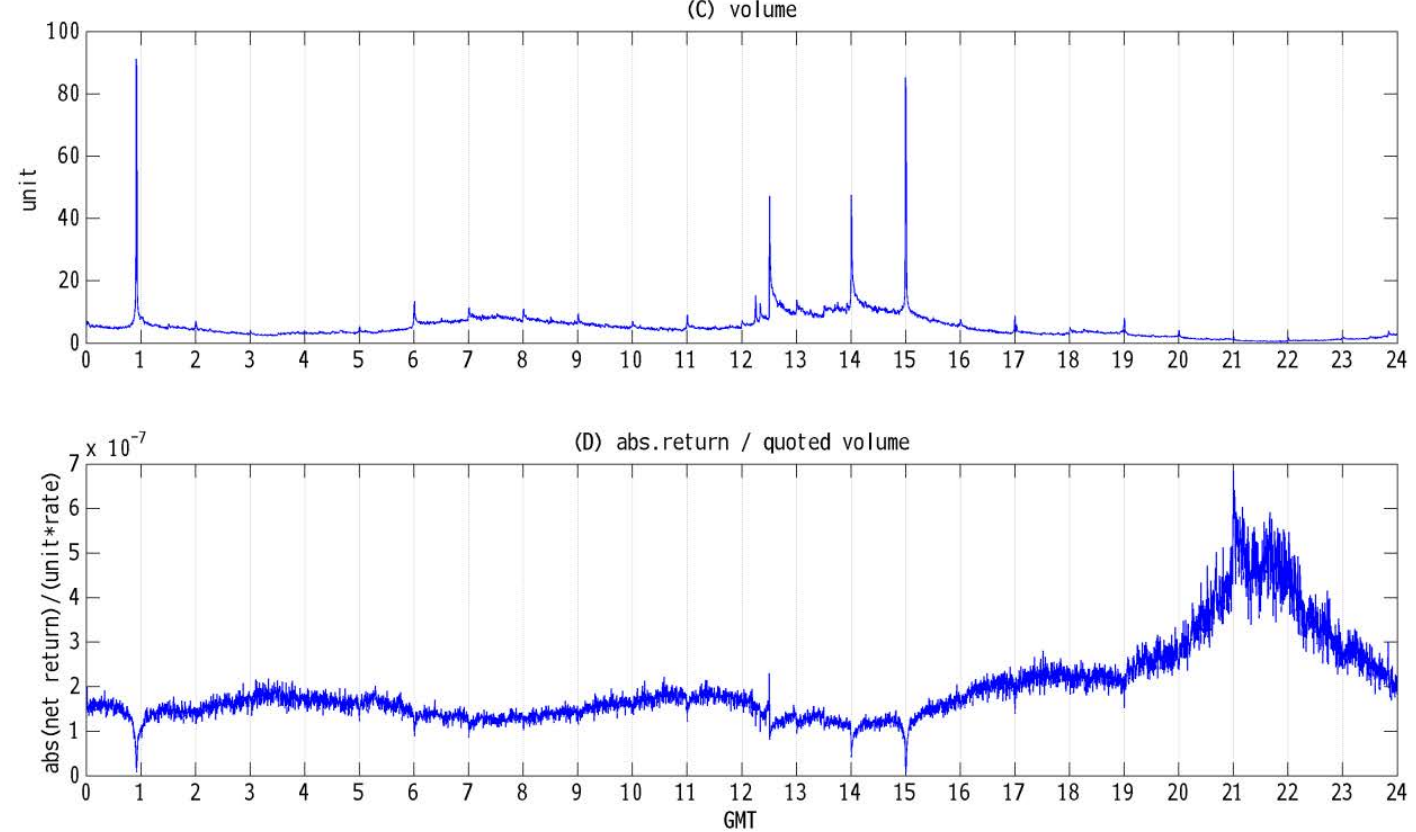

Figure 2: Intraday patterns of four variables

Intraday patterns of USD/JPY (from January 4, 2006 to December 31, 2013) for: (A) The ratio of absolute order imbalances to trading volumes, (B) the order imbalances (unit is one million currency), (C) the trading volumes (unit is one million currency pair unit), and (D) the price impact (unit is log price changes for each one million yen trades). The sample is from the days that both US and UK are under daylight saving time. Each variable is averaged across days for every 15 seconds. The horizontal axis is the time of GMT. The four major peeks of trading volumes correspond to: (1) The Tokyo fixing (GMT 00:55), (2) US macro announcement (GMT 12:30), (3) New York currency option cut (GMT 14:00), (4) the London Fixing (GMT 15:00). 
(A) Sum of bid and of fer LO volume, USD-JPY

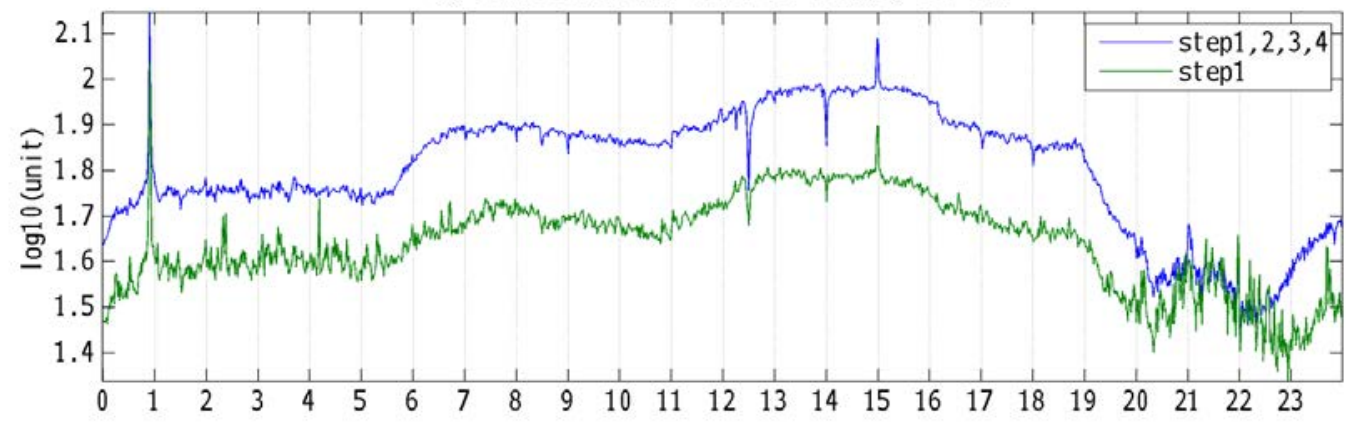

(B) (Bid - Offer L0 volume)/total volume

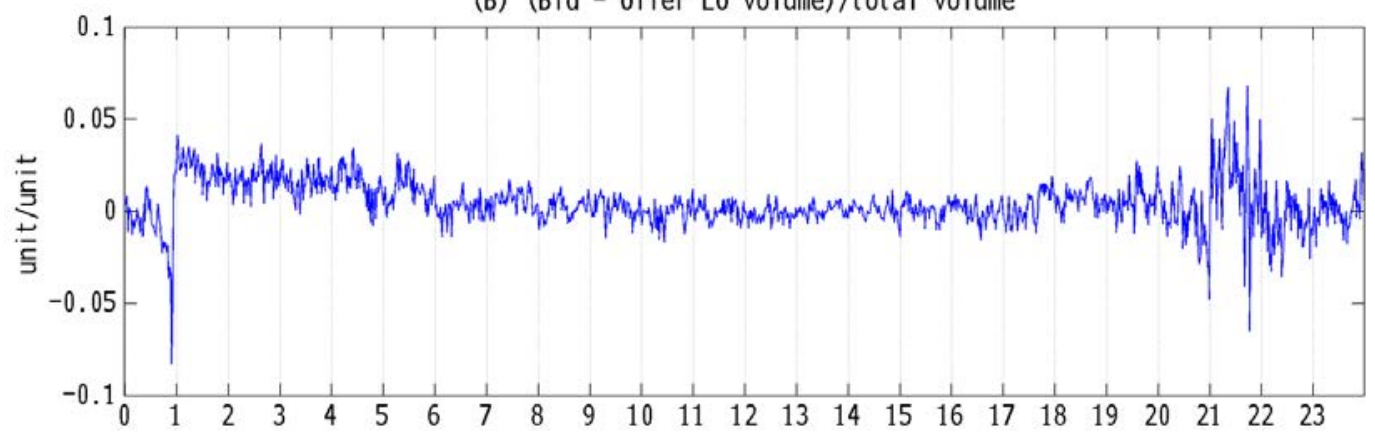

(C) Quote counts

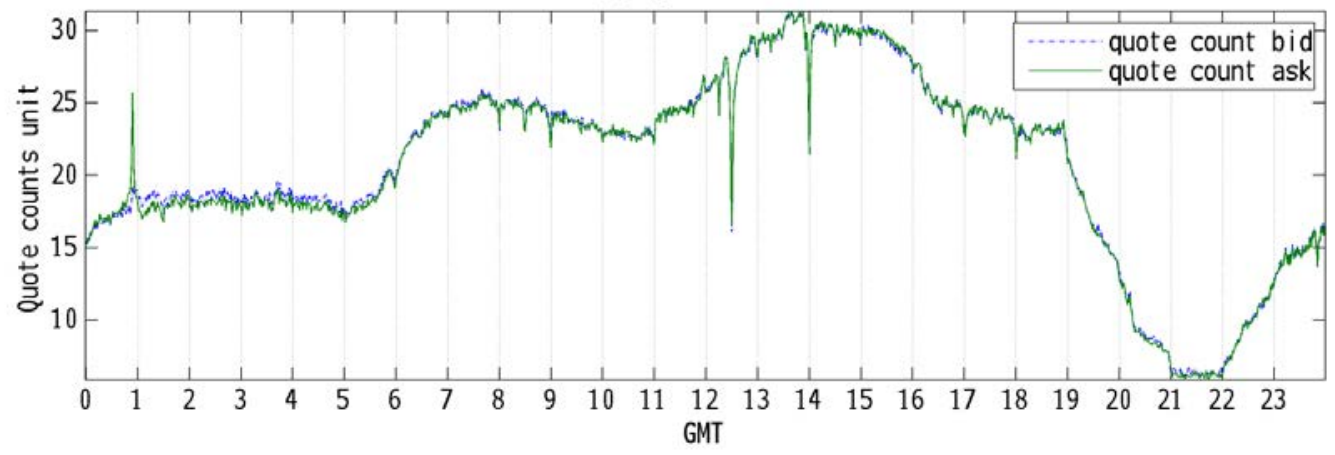

Figure 3: Intraday pattern of limit order books

These panels show intraday pattern of the limit order book: (A) The common log of the sum of bid and ask side limit order volumes up to four steps (blue) and the best quote (green). (B) The difference between the bid limit order volumes and the offer limit order volumes. The values are divided by the total limit order volume. (C) The quote counts, or the number of counterparties behind the quotes, for the bid and ask side books. The sample is from the days that both US and UK are under daylight saving time. Each variable is averaged across days for every 60 seconds. The horizontal axis is the time of GMT. 
EUR/JPY
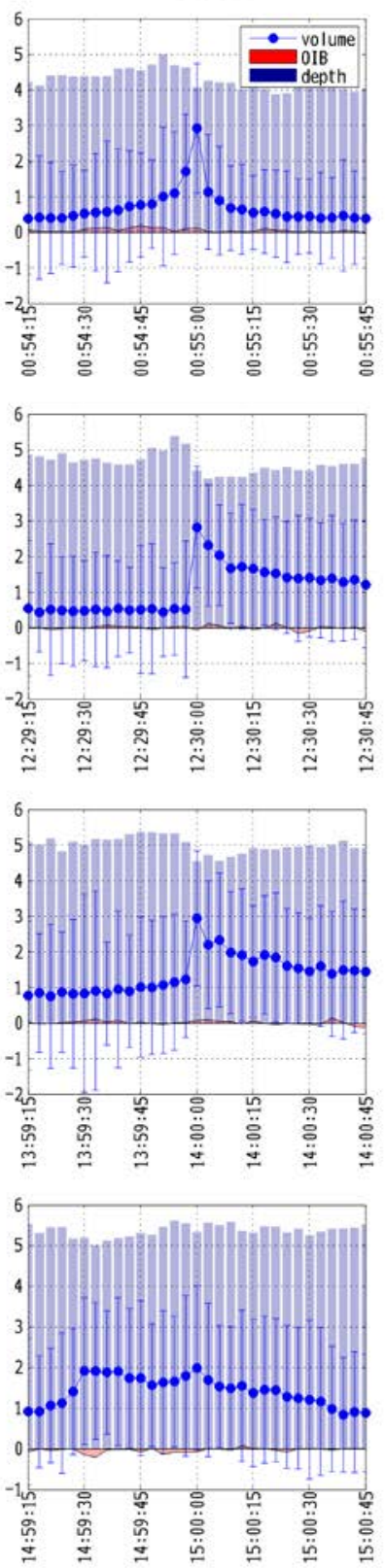

EURUSD
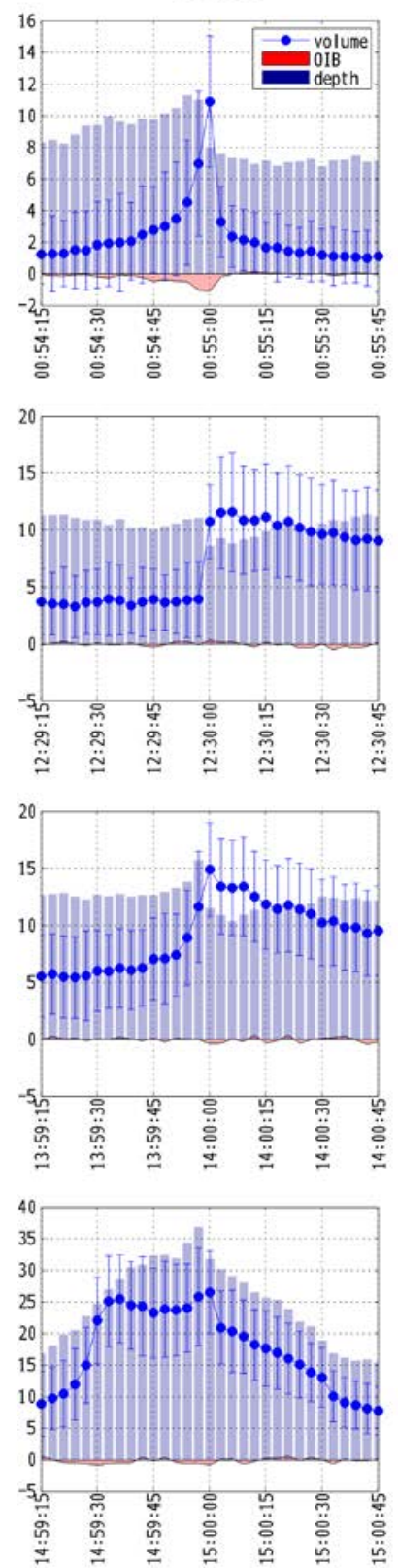

USD/JPY
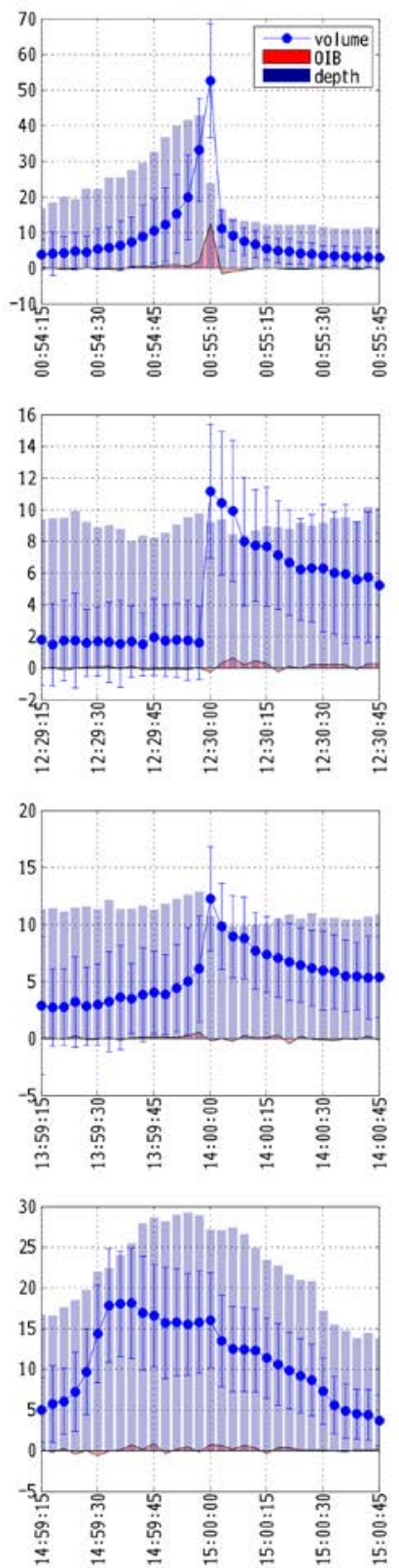

Figure 4: 90-second window around four events

This is a plot of the trading volumes (and their one standard deviation bars across days), the order imbalances, and the depth (the sum of best bid and ask limit order volumes). Each variable is the average across days for every three seconds. We focus on 90 seconds around the Tokyo fixing (GMT 00:55), US macro announcement (GMT 12:30), NY option cut (GMT 14:00), the London fixing (GMT 15:00). The horizontal axis is GMT and the vertical axis is the unit of deals. 
Table 2: One-minute relative frequency of spikes across days

\begin{tabular}{|c|c|c|c|c|c|c|c|c|c|c|c|c|c|c|}
\hline & \multicolumn{7}{|c|}{ EUR/USD } & \multicolumn{7}{|c|}{ USD/JPY } \\
\hline & b0055 & j0055 & a0055 & b1500 & j1500 & a1500 & all & b0055 & j0055 & a0055 & b1500 & j1500 & a1500 & all \\
\hline all & 0.044 & 0.324 & 0.057 & 0.081 & 0.218 & 0.091 & 0.059 & 0.037 & 0.247 & 0.048 & 0.052 & 0.153 & 0.057 & 0.040 \\
\hline 5-10day & 0.045 & 0.358 & 0.062 & 0.082 & 0.206 & 0.099 & 0.059 & 0.038 & 0.276 & 0.044 & 0.050 & 0.155 & 0.051 & 0.037 \\
\hline Friday & 0.047 & 0.394 & 0.049 & 0.099 & 0.278 & 0.106 & 0.064 & 0.036 & 0.301 & 0.059 & 0.075 & 0.260 & 0.070 & 0.046 \\
\hline End of month & 0.060 & 0.634 & 0.060 & 0.164 & 0.895 & 0.168 & 0.062 & 0.052 & 0.538 & 0.089 & 0.086 & 0.737 & 0.162 & 0.042 \\
\hline 2006 & 0.009 & 0.147 & 0.014 & 0.029 & 0.091 & 0.028 & 0.016 & 0.008 & 0.052 & 0.015 & 0.022 & 0.107 & 0.023 & 0.013 \\
\hline 2007 & 0.009 & 0.140 & 0.007 & 0.011 & 0.043 & 0.015 & 0.013 & 0.013 & 0.113 & 0.019 & 0.019 & 0.074 & 0.024 & 0.021 \\
\hline 2008 & 0.131 & 0.914 & 0.139 & 0.266 & 0.663 & 0.269 & 0.167 & 0.136 & 0.643 & 0.169 & 0.222 & 0.612 & 0.240 & 0.146 \\
\hline 2009 & 0.099 & 0.717 & 0.115 & 0.185 & 0.475 & 0.228 & 0.134 & 0.085 & 0.616 & 0.088 & 0.097 & 0.256 & 0.122 & 0.073 \\
\hline 2010 & 0.053 & 0.354 & 0.092 & 0.067 & 0.190 & 0.089 & 0.056 & 0.027 & 0.195 & 0.039 & 0.025 & 0.101 & 0.031 & 0.025 \\
\hline 2011 & 0.039 & 0.181 & 0.077 & 0.068 & 0.200 & 0.073 & 0.058 & 0.012 & 0.162 & 0.041 & 0.007 & 0.027 & 0.009 & 0.018 \\
\hline 2012 & 0.009 & 0.058 & 0.008 & 0.015 & 0.031 & 0.02 & 0.016 & 0.004 & 0.074 & 0.005 & 0.006 & 0.019 & 0.003 & 0.006 \\
\hline 2013 & 0.000 & 0.082 & 0.002 & 0.009 & 0.054 & 0.007 & 0.009 & 0.007 & 0.121 & 0.008 & 0.016 & 0.027 & 0.006 & 0.015 \\
\hline
\end{tabular}

This table describes the one-minute relative frequency of spikes across days. The spikes are defined as the reversal among large price shocks. Each presented value is the counts of spikes divided by the number of days multiplied by the minutes of the interval (i.e., number of days *10 for 10 minute interval, for example). Each column categorizes the intraday time period: prefix "b" (or "a") stands for the 10 minute interval before (or after) the time, and "j" stands for the one minute interval around the time. Each row shows the statistics for sub-samples: "all" use the whole sample, " $5-10$ day" use the $5^{\text {th }}$ and $10^{\text {th }}$ days, and "Friday" use the Friday sample, "End of month" use the sample at the last trading day in each month. Other rows use the sub-samples for each year. 

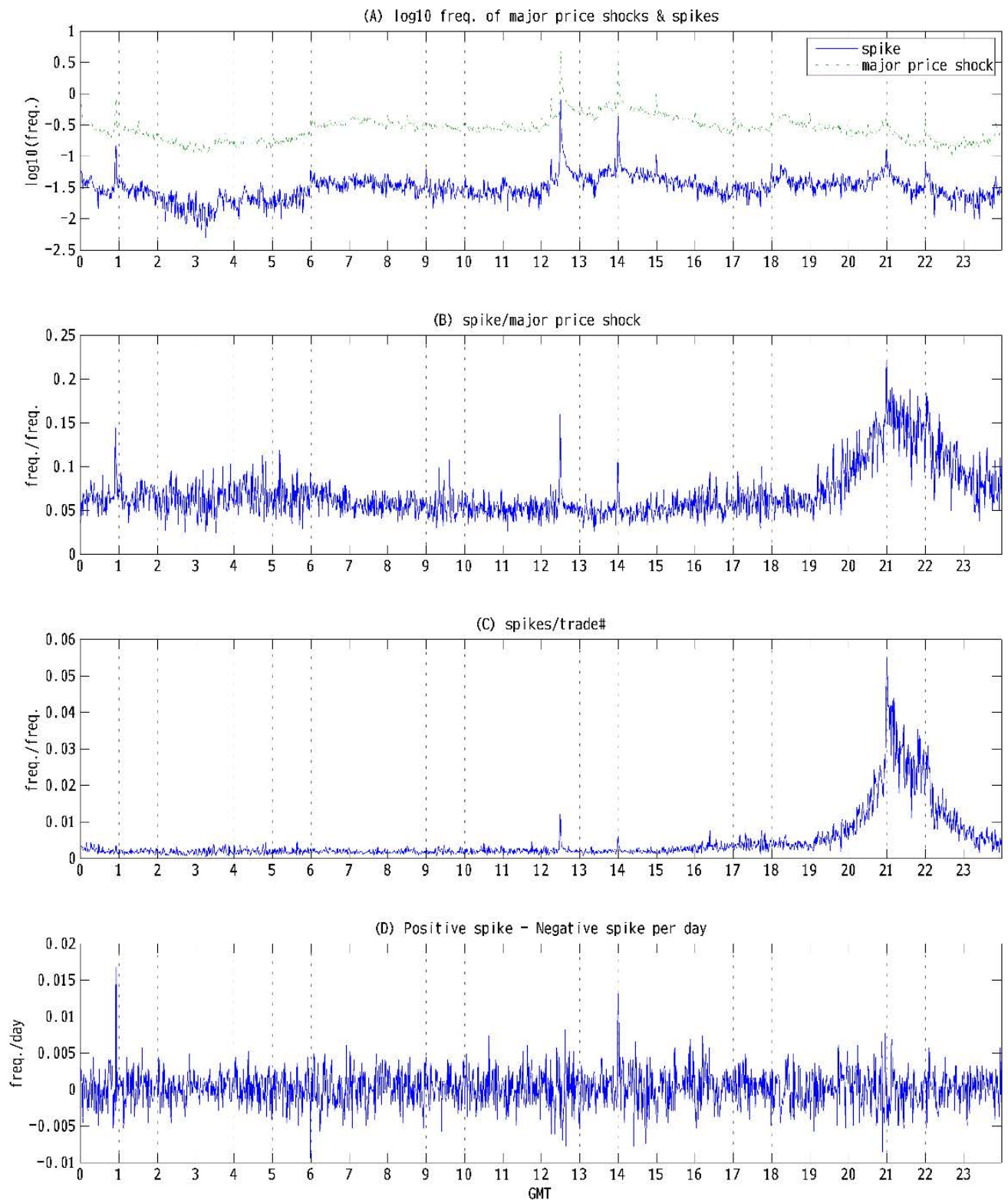

Figure 5: Intraday pattern of spikes

These panels show the frequency of spikes with various normalizations. (A) The common log of the frequency of spikes and major price shocks. (B) The frequency of spikes divided by the frequency of major price changes. (C) The frequency of spikes divided by the frequency of deals. (D) The difference between the frequency of positive spikes and the frequency of negative spikes. The sample is from the days that both US and UK are under daylight saving time. Each variable is averaged across days for every 60 seconds. The horizontal axis is the time of GMT. 
Table 3: Regression analysis for the frequency of spikes

\begin{tabular}{|c|c|c|c|c|}
\hline \multicolumn{5}{|c|}{$\mathrm{y}=$ frequency of spike per minute } \\
\hline & EUR/JPY & EUR/USD & USD/CHF & USD/JPY \\
\hline alpha & $\begin{array}{c}0.376 * * * \\
(5.58)\end{array}$ & $\begin{array}{c}0.472 * * * \\
(91.6)\end{array}$ & $\begin{array}{c}0.348 * * * \\
(38.6)\end{array}$ & $\begin{array}{c}0.417 * * * \\
(321)\end{array}$ \\
\hline numb. trade & $\begin{array}{c}0.452 * * * \\
(5.46)\end{array}$ & $\begin{array}{c}0.933 * * * \\
(15.6)\end{array}$ & $\begin{array}{c}0.5 * * * \\
(31.9)\end{array}$ & $\begin{array}{c}0.843 * * * \\
(199)\end{array}$ \\
\hline trade size & $\begin{array}{c}-0.248 * * * \\
(-10.6)\end{array}$ & $\begin{array}{l}0.0771 \\
(1.24)\end{array}$ & $\begin{array}{c}-0.0374 * * * \\
\quad(-3.73)\end{array}$ & $\begin{array}{c}-0.079 * * * \\
(-13.7)\end{array}$ \\
\hline end of month & $\begin{array}{l}-0.0359 \\
(-0.766)\end{array}$ & $\begin{array}{l}0.0306 \\
(0.896)\end{array}$ & $\begin{array}{l}-0.042 \\
(-1.13)\end{array}$ & $\begin{array}{l}-0.0207 \\
(-1.12)\end{array}$ \\
\hline Friday & $\begin{array}{c}0.13 * * * \\
(2.7)\end{array}$ & $\begin{array}{c}0.122 * * \\
(2.08)\end{array}$ & $\begin{array}{c}0.09 * * * \\
(4.77)\end{array}$ & $\begin{array}{c}0.073 * * * \\
(7.31)\end{array}$ \\
\hline $\begin{array}{l}\text { gaps from } \\
\text { VWAP }\end{array}$ & $\begin{array}{c}0.545 * * * \\
(25.9) \\
\end{array}$ & $\begin{array}{c}0.82 * * * \\
(60)\end{array}$ & $\begin{array}{c}0.859 * * * \\
(31.4) \\
\end{array}$ & $\begin{array}{c}0.774 * * * \\
(39.5) \\
\end{array}$ \\
\hline Tokyo fix & & & & \\
\hline b0055 & $\begin{array}{c}-0.0979 \\
(-1.23)\end{array}$ & $\begin{array}{c}-0.00509 \\
(-0.04)\end{array}$ & $\begin{array}{c}-0.16 * * \\
(-2.16)\end{array}$ & $\begin{array}{c}0.157 * * * \\
(3.33)\end{array}$ \\
\hline j0055 & $\begin{array}{c}\mathbf{0 . 8 8 5} * * * \\
(13.3)\end{array}$ & $\begin{array}{c}1.24 * * * \\
(21.3)\end{array}$ & $\begin{array}{c}\mathbf{0 . 4 6 9} * * * \\
(2.86)\end{array}$ & $\begin{array}{c}1.08 * * * \\
(42.5)\end{array}$ \\
\hline $\mathrm{a} 0055$ & $\begin{array}{c}-0.133 * \\
(-1.42)\end{array}$ & $\begin{array}{c}0.063 \\
(0.738) \\
\end{array}$ & $\begin{array}{l}0.0163 \\
(0.192) \\
\end{array}$ & $\begin{array}{c}0.147 * * * \\
(4.1)\end{array}$ \\
\hline London fix & & & & \\
\hline b1500 & $\begin{array}{c}0.193 * * \\
(2.25)\end{array}$ & $\begin{array}{c}0.116 * * * \\
(3.01)\end{array}$ & $\begin{array}{l}0.103 \\
(1.16)\end{array}$ & $\begin{array}{c}0.116 * * * \\
(4.41)\end{array}$ \\
\hline j1500 & $\begin{array}{c}0.254 * \\
(1.31)\end{array}$ & $\begin{array}{c}-1.13 * * * \\
(-9.21)\end{array}$ & $\begin{array}{c}\mathbf{- 0 . 4 0 4} * * \\
(-2.31)\end{array}$ & $\begin{array}{c}-1.01 * * * \\
(-27.8)\end{array}$ \\
\hline a1500 & $\begin{array}{c}0.173 * * \\
(1.92)\end{array}$ & $\begin{array}{c}0.0613 * \\
(1.28)\end{array}$ & $\begin{array}{c}0.138 * \\
(1.45) \\
\end{array}$ & $\begin{array}{c}0.136 * * * \\
(4.14) \\
\end{array}$ \\
\hline BA spread & $\begin{array}{c}0.629 * * * \\
(3.75)\end{array}$ & $\begin{array}{c}9.77 * * * \\
(64.3)\end{array}$ & $\begin{array}{c}0.434 \text { *** } \\
(27.4)\end{array}$ & $\begin{array}{c}1.29 * * * \\
(79)\end{array}$ \\
\hline depth & $\begin{array}{c}-1.32 * * * \\
(-27.1)\end{array}$ & $\begin{array}{c}-0.663 * * * \\
(-11.3)\end{array}$ & $\begin{array}{c}-0.823 * * * \\
(-28.2)\end{array}$ & $\begin{array}{c}-2.11 * * * \\
(-45.1)\end{array}$ \\
\hline quote count & $\begin{array}{c}0.609 * * * \\
(9.23)\end{array}$ & $\begin{array}{c}-0.251 * * * \\
(-30)\end{array}$ & $\begin{array}{c}-0.307 * * * \\
(-14.3)\end{array}$ & $\begin{array}{c}-0.113 * * * \\
(-12.2)\end{array}$ \\
\hline constant & $\begin{array}{c}-4.49 * * * \\
(-186)\end{array}$ & $\begin{array}{c}-3.24 * * * \\
(-41.5)\end{array}$ & $\begin{array}{c}-4.56 * * * \\
(-279)\end{array}$ & $\begin{array}{c}-3.76 * * * \\
(-287)\end{array}$ \\
\hline \# of obs & 1279423 & 1706061 & 1214228 & 1674521 \\
\hline R squared & 0.32566 & 0.43037 & 0.34424 & 0.44779 \\
\hline
\end{tabular}

The estimation results for the frequency of spikes and average-median price gaps. The sampling frequency of the variables is a minute.

[Dependent variables] We take the frequency of spikes per minute (left panel) and average-median price gap (or absolute value of $\log$ (averaged price) - $\log$ (median price), right panel) as dependent variables.

[Independent variables] Independent variables include the dummies for the events: Tokyo fixing, US macro announcement, NY option cut, and London fixing. Each event has three dummies that indicate plus and minus 30 seconds around the event time, 10 minutes interval before and after the event. For the sake of brevity, we only present the estimates for the fixing dummies. We also add control variables: the number of trades per minute, trade 
sizes, the difference between the market price and the VWAP, Friday and end of month dummies. We also control the effect from the limit order book: the bid-ask spreads, the depths, and the quote counts. Since our sample includes the decimalized period, we implement the separate estimation for each period. Here, we present only the estimates before the pips were decimalized (from January 5, 2006 to March 6, 2011). ***, **, and * denote levels significantly different from zero at the 1 percent, 5 percent, and 10 percent, respectively.

[Methodology] The number of trades, trade sizes, bid-ask spreads, depth and quote counts are standardized. For the left panel, we conducted Negative binomial regression for the count of spikes and over-dispersion parameter $\alpha$ is also estimated and presented. R-squared measure is that based on the deviance residual (Cameron and Windmeijer (1996)).

[Notes on sample and methodology] Our sample ranges from January 5, 2006 to March 6, 2011. The currency pairs are EUR/JPY, EUR/USD, USD/CHF, and USD/JPY. Each variable is constructed as one-minute by one-minute variables. The number of trades is the sum during each minute. The trade size, bid-ask spread, depth, quote count, and VWAP are the average during each minute. We can conduct the same analysis for the decimalized period after March 6, 2011, but the overall results are similar. We can also separate the samples to day-by-day or month-bymonth and use reversed Fama-MacBeth method for calculating the standard errors, which also gives the similar qualitative results. 
Table 4: Negative correlation around events

\begin{tabular}{|c|c|c|c|c|}
\hline & & EUR/JPY & EUR/USD & USD/JPY \\
\hline Sample & $\begin{array}{c}\text { Interval } \\
\text { (min) }\end{array}$ & Tokyo Fix & Tokyo Fix & Tokyo Fix \\
\hline \multirow[t]{10}{*}{ All } & 1 & -0.00411 & $-0.0393 *$ & 0.0154 * \\
\hline & & $(0.852)$ & (0.0738) & (0.0738) \\
\hline & 5 & -0.00594 & 0.0198 & -0.00728 \\
\hline & & $(0.787)$ & $(0.367)$ & $(0.367)$ \\
\hline & 10 & 0.00503 & 0.000179 & -0.00421 \\
\hline & & (0.819) & (0.994) & (0.994) \\
\hline & 15 & -0.0162 & -0.013 & 0.0133 \\
\hline & & $(0.463)$ & $(0.554)$ & $(0.554)$ \\
\hline & 30 & 0.0306 & -0.00334 & 0.0512 \\
\hline & & $(0.164)$ & (0.879) & $(0.879)$ \\
\hline \multirow[t]{10}{*}{ Friday } & 1 & -0.0376 & $-0.107 * *$ & $0.0525 * *$ \\
\hline & & $(0.446)$ & $(0.0296)$ & (0.0296) \\
\hline & 5 & -0.0251 & -0.000843 & 0.0515 \\
\hline & & $(0.611)$ & $(0.986)$ & $(0.986)$ \\
\hline & 10 & 0.052 & -0.0424 & 0.0473 \\
\hline & & $(0.291)$ & (0.389) & (0.389) \\
\hline & 15 & 0.0257 & $-0.0935 *$ & $0.0814 *$ \\
\hline & & (0.602) & $(0.0574)$ & $(0.0574)$ \\
\hline & 30 & 0.0751 & $-0.0864 *$ & $0.122 *$ \\
\hline & & $(0.127)$ & $(0.0791)$ & (0.0791) \\
\hline \multirow{10}{*}{$\begin{array}{l}\text { End-of } \\
\text { Month }\end{array}$} & 1 & -0.0801 & -0.0859 & -0.0829 \\
\hline & & $(0.438)$ & $(0.405)$ & $(0.405)$ \\
\hline & 5 & 0.0438 & $0.257 * *$ & $0.0196 * *$ \\
\hline & & (0.672) & $(0.0114)$ & $(0.0114)$ \\
\hline & 10 & 0.027 & 0.0342 & 0.0538 \\
\hline & & $(0.794)$ & $(0.741)$ & $(0.741)$ \\
\hline & 15 & -0.0188 & 0.0958 & 0.0278 \\
\hline & & $(0.856)$ & $(0.353)$ & $(0.353)$ \\
\hline & 30 & 0.0764 & 0.0475 & 0.137 \\
\hline & & (0.459) & $(0.646)$ & $(0.646)$ \\
\hline
\end{tabular}

This panel shows the Spearman's correlation of returns before and after each fixing event time window (GMT 00:55:00 and GMT 15:00:00). Each parenthesis indicates the p-value. The remarkable significant negative correlations are shadowed. The intervals for calculating the return are one, five, ten, fifteen, and thirty minutes before GMT00:54:30 (or GMT14:59:30) and after GMT00:55:30 (or GMT 15:00:30). The null hypothesis is zero correlation. The negative correlation indicates a return reversal. ${ }^{* *}$, **, and $*$ denote levels significantly different from zero at the 1 percent, 5 percent, and 10 percent, respectively. 

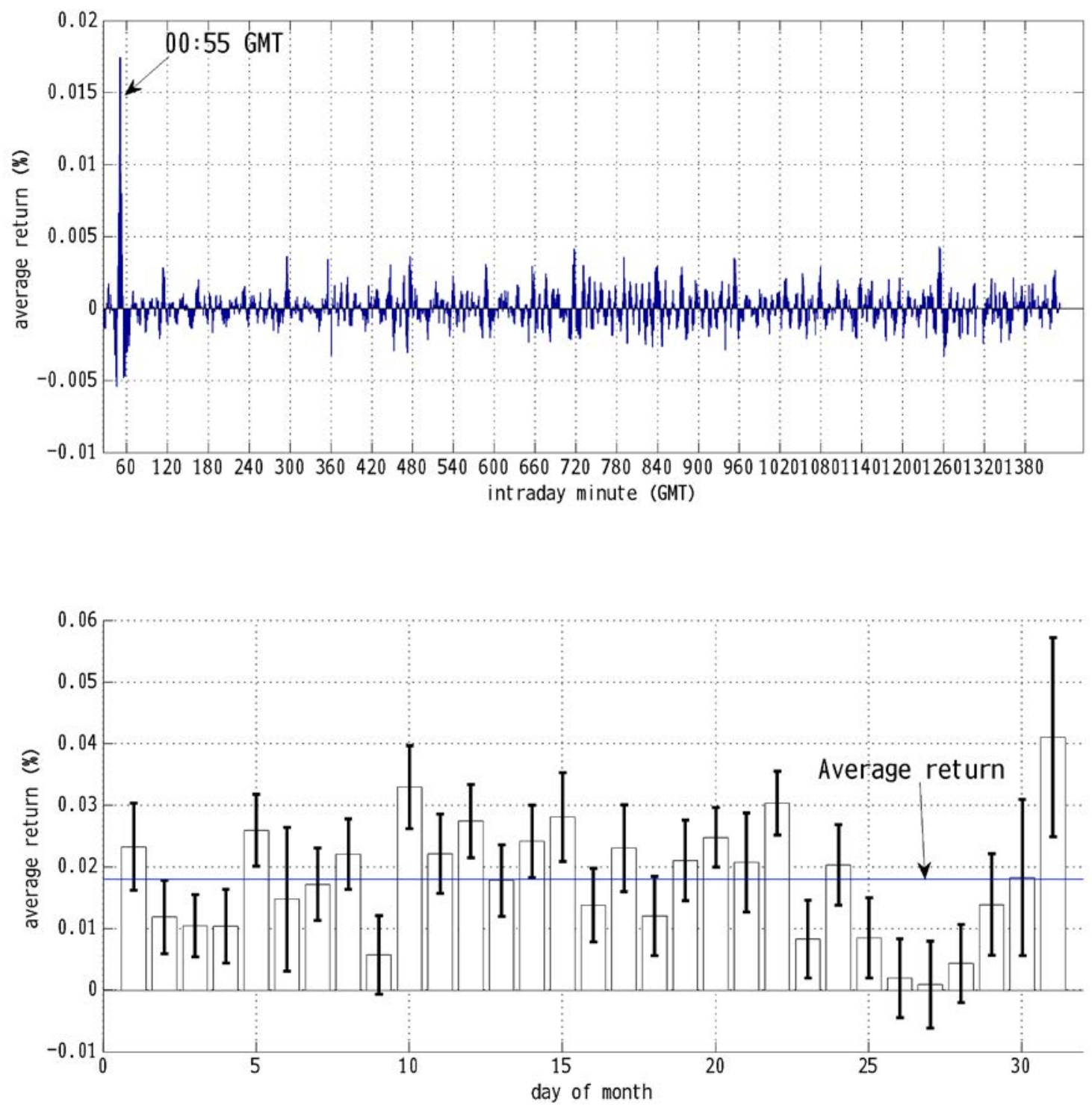

Figure 6: Average return of five minutes long and short position

These figures present the average return of investment that holds five minutes of long and five minutes of short position (USD/JPY) around scheduled time of each day. The top panel shows the average return (truncating $1 \%$ of the top and bottom) over 15 years (from January 1999 to December 2013, total of 4111 days). The horizontal axis is the intraday time (in minute, GMT) when the long and short position switches. The bottom panel is the average return of the investment switching the position at 00:55GMT (or Tokyo fixing time) over each day of month. The error bars express positive and minus one standard error. The blue horizontal line represents the overall average return. The return is calculated from the transaction prices and the transaction cost is not considered. 

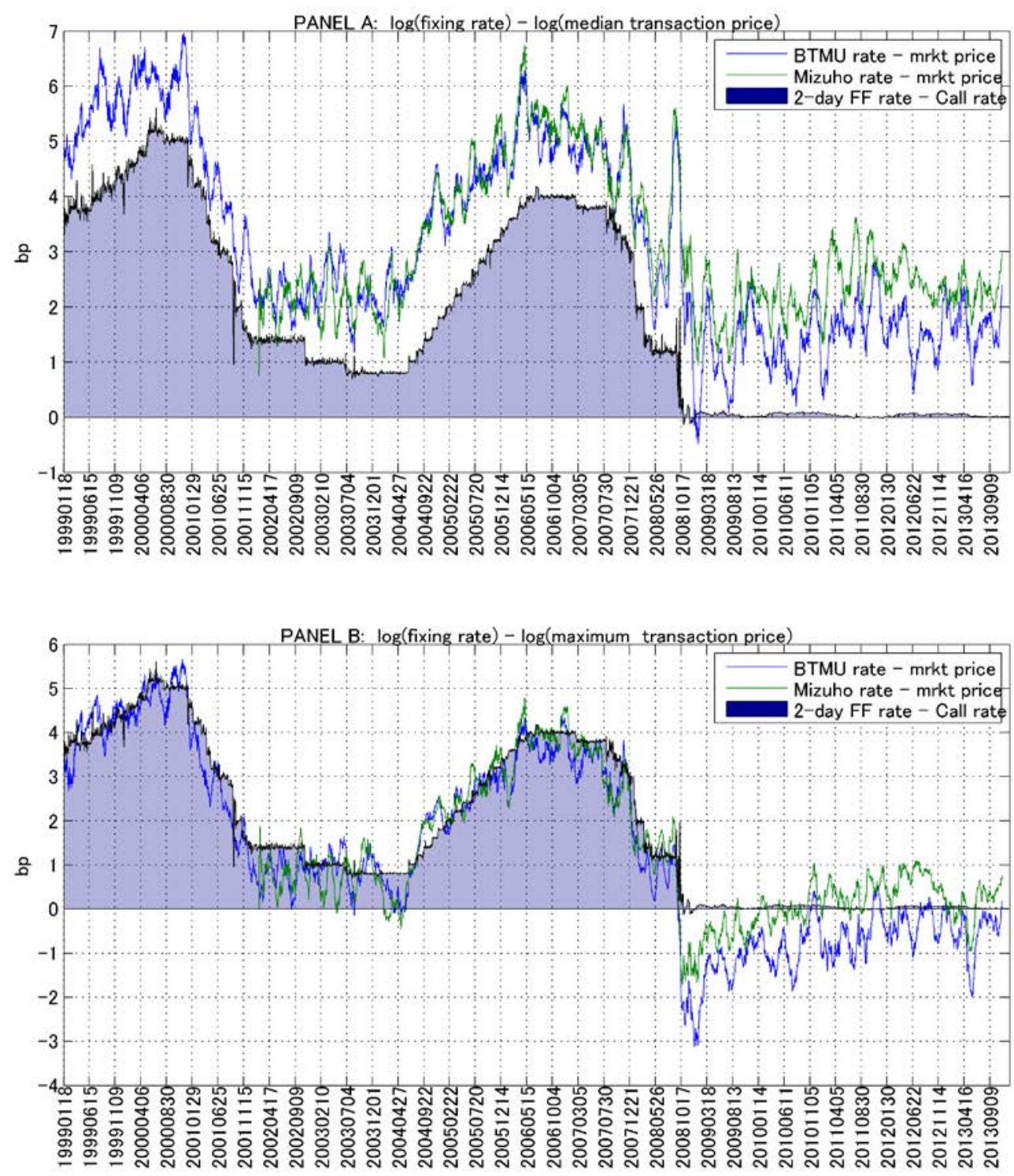

\section{Figure 7: Time series pattern of the difference between the Tokyo fixing rate and the market rates (panel A. average and panel B. max) during the fixing window (USD/JPY)}

This panels show 30 days moving averages for the gaps between the Tokyo fixing rates and the market rate that we calculated from EBS data in the Tokyo fixing window. The area-plot is the two day interest differentials between the US FF rate and Call rate in Japan (or $2 *(\mathrm{FF}$ rate - Call rate)/250). The gap (in basis point) is defined as $[\log$ (fixing rate) $-\log ($ market rate $)] \times 10000$. The market rate is calculated as a "maximum" and "median" transaction price for the sample starting from GMT 00:55:00 to GMT 00:55:59, for top and bottom panels. For the fixing rates, we use the rates that each bank (the BTMU and Mizuho bank) publishes on their web sites. The currency pair is USD/JPY. 
Table 5: Regression analysis for the Tokyo fixing - max gaps

\begin{tabular}{|c|c|c|c|c|}
\hline & \multicolumn{2}{|c|}{ Use maximum event price } & \multicolumn{2}{|c|}{ Use median event price } \\
\hline \multirow{3}{*}{ Volatility (before) } & Mizuno, USD/JPY & BIIMU, USD/JPY & MIIZUnO, USD/JPY & BIIVU, USD/JPY \\
\hline & $-0.474 * * *$ & $-0.558 * * *$ & $0.215 * *$ & 0.122 \\
\hline & {$[-5.77]$} & {$[-6.88]$} & {$[2.14]$} & [1.16] \\
\hline \multirow[t]{2}{*}{ OIB (before) } & 3.96e-08 & 7.19e-08 *** & $8.72 \mathrm{e}-08 * * *$ & $1.21 \mathrm{e}-07 * * *$ \\
\hline & {$[1.24]$} & {$[2.34]$} & {$[2.34]$} & [3.39] \\
\hline \multirow[t]{2}{*}{ Return (before) } & $0.00841 * * *$ & $0.00593 * *$ & $0.0108 * *$ & $0.0084 * *$ \\
\hline & {$[2.43]$} & {$[2.1]$} & {$[2.22]$} & {$[2.05]$} \\
\hline \multirow[t]{2}{*}{ Price - VWAP } & $0.0459 * * *$ & $0.065 * * *$ & $0.0471 * * *$ & $0.0659 * * *$ \\
\hline & {$[3.8]$} & {$[6.07]$} & {$[3.37]$} & {$[5.21]$} \\
\hline \multirow[t]{2}{*}{$\operatorname{Lag}(1)$ of $y$} & $0.0568 * * *$ & $0.101 * * *$ & $0.0837 * * *$ & $0.0863 * * *$ \\
\hline & [2.91] & {$[5.34]$} & [4.25] & {$[4.36]$} \\
\hline \multirow[t]{2}{*}{ 5th and 10th days } & $1.73 \mathrm{e}-05 * *$ & $5.17 \mathrm{e}-05 * * *$ & $4.38 \mathrm{e}-05 * * *$ & $7.82 \mathrm{e}-05 * * *$ \\
\hline & {$[1.96]$} & {$[5.85]$} & {$[4.23]$} & {$[7.64]$} \\
\hline \multirow[t]{2}{*}{ Friday } & $6.68 \mathrm{e}-05 * * *$ & $8.9 \mathrm{e}-05 * * *$ & $8.98 \mathrm{e}-05 * * *$ & $0.000115^{* * *}$ \\
\hline & {$[6.76]$} & {$[9.63]$} & {$[8.01]$} & {$[11.4]$} \\
\hline \multirow[t]{2}{*}{ End of Month } & $-1.24 \mathrm{e}-05$ & $5.28 \mathrm{e}-05 * * *$ & $3.87 \mathrm{e}-05 *$ & $0.000103 * * *$ \\
\hline & {$[-0.58]$} & {$[2.67]$} & {$[1.44]$} & [3.99] \\
\hline \multirow[t]{2}{*}{ US FF rate - Call rate } & $6.8 \mathrm{e}-05 * * *$ & $7.59 \mathrm{e}-05 * * *$ & $5.86 \mathrm{e}-05 * * *$ & $6.98 \mathrm{e}-05 * * *$ \\
\hline & {$[28.8]$} & {$[29.6]$} & [21.4] & {$[24.1]$} \\
\hline \multirow[t]{2}{*}{ Constant } & $4.5 \mathrm{e}-05 * * *$ & $-1.4 \mathrm{e}-05$ & $0.000125 * * *$ & $6.5 \mathrm{e}-05 * * *$ \\
\hline & {$[3.76]$} & {$[-1.21]$} & {$[7.65]$} & {$[4.17]$} \\
\hline \# of observation & 2846 & 2846 & 2846 & 2846 \\
\hline Adjusted R squared & 0.3675 & 0.466 & 0.2625 & 0.3662 \\
\hline
\end{tabular}

This regression analysis describes the gaps between the Tokyo fixing rates and the maximum market rates. The regression equation is as follows. The sample is day-by-day.

$$
\begin{aligned}
& \log \left(\text { Fix }_{d}\right)-\log \left(P_{d}\right)=\alpha+\beta_{1} \text { Before. volatility } y_{d}+\beta_{2} \text { Before. OIB }{ }_{d}+\beta_{3} \text { Before.cumRet }_{d}+\beta_{4}\left(\log \left(P_{d}\right)-\log \left(V W A P_{d}\right)\right) \\
& +\beta_{5} \text { lag of indep }+\beta_{6} \text { Interest rate differential }+ \text { Dummies }+\epsilon_{d}
\end{aligned}
$$

"Before" means that the variable is calculated from the sample from GMT 00:00 to GMT 00:55.

[Dependent variable] The dependent variables are the log differences between the fixing rate and the maximum market price. As a reference of the market price, we take "maximum" of the transaction price during fixing, or 60 seconds from JST 9:55 (GMT 00:55). The currency pairs is USD/JPY. We use the samples of fixing rate from the Mizuho bank and the BTMU. [Independent variables] The independent variables are: one minute return volatility, sum of the order imbalances (OIB), cumulative returns, differences of log prices of $\mathrm{P}_{d}$ and volume weighted average prices (VWAP), one lag of the independent variable, and calendar dummies. The volatility, OIB, and returns are calculated from the sample from GMT 00:00 to GMT 00:55. Calendar dummies are the date of $5^{\text {th }}$ and $10^{\text {th }}$ days, Friday, and the last trading day of each month. Here we add the dummy of $5^{\text {th }}$ and $10^{\text {th }}$ days considering the Japanese traditions. ${ }^{* *}, * *$, and * denote levels significantly different from zero at the 1 percent, 5 percent, and 10 percent, respectively. [Methodology] The regression is done though OLS. The standard errors are corrected by the Newey-West method. [Notes on sample] The sample of the fixing rate from Mizuho bank is from May 16, 2002 to Dec 30, 2013. The sample of the fixing rate from BTMU is from January 5, 1999 to Dec 30, 2013. 


\section{Table 6: Tokyo fixing USD/JPY rate and the EBS market rate (median or max)}

\begin{tabular}{|c|c|c|c|c|c|c|c|c|c|c|}
\hline period & Bank/Method & mean & median & std & skewness & kurtosis & $\mathrm{q} 1$ & q99 & Lowest day & Highest day \\
\hline Before Nov.2008 & BTMU, median & 4.03 & 3.74 & 2.64 & 0.465 & 3.52 & -1.65 & 11.3 & 20040422 & 20000303 \\
\hline After Nov.2008 & BTMU, median & 1.46 & 1.3 & 2.41 & -0.0409 & 4.23 & -4.47 & 7.61 & 20100901 & 20110901 \\
\hline Before Nov.2008 & BTMU, max & 2.47 & 2.47 & 2.51 & 0.152 & 3.74 & -3.74 & 8.8 & 20080930 & 20071227 \\
\hline After Nov.2008 & BTMU,,max & -0.79 & 0 & 2.15 & -1.2 & 5.84 & -7.44 & 2.65 & 20090128 & 20081230 \\
\hline Before Nov.2008 & Mizuho, median & 3.64 & 3.56 & 2.56 & 0.303 & 3.9 & -1.96 & 10.1 & 20060303 & 20071228 \\
\hline After Nov.2008 & Mizuho, median & 2.32 & 2.47 & 2.25 & -0.111 & 5.82 & -3.71 & 8.18 & 20130614 & 20090331 \\
\hline Before Nov.2008 & Mizuho, max & 2 & 1.91 & 2.37 & -0.262 & 4.28 & -4.63 & 7.63 & 20060303 & 20071227 \\
\hline After Nov.2008 & Mizuho, max & 0.058 & 0.988 & 1.93 & -1.91 & 9.05 & -7.08 & 3.2 & 20090128 & 20110810 \\
\hline
\end{tabular}

This table is the summary statistics of the gaps between the Tokyo fixing rates and the median and maximum market rate at the EBS market during the Tokyo fixing window. The gap (in basis point) is defined as $[\log$ (fixing rate) $-\log ($ market rate $)] \times 10000$. The market rate is calculated as either "median" or "maximum" transaction price for the sample starting from GMT 00:55:00 (for summer time) to GMT 00:55:59. For the fixing rates, we use the rates that each bank (the BTMU and Mizuho bank) publishes on their web sites. 